\title{
Proceso de gestión del Proyecto de Tecnologías Móviles: Estudio de caso
}

\author{
Management process of the project of mobile technologies: A case study
}

Recibido 29 octubre 2013 • Aceptado 05 diciembre 2013 • Corregido 11 diciembre 2013

\author{
Hazel Castro Araya \\ Ministerio de Educación Pública \\ San José, Costa Rica \\ hazelcastroaraya@gmail.com
}

\begin{abstract}
Resumen. El artículo resume la gestión del Proyecto Nacional de Tecnología Móvil, que se ha implementado en forma piloto, por la Fundación Omar Dengo en tres escuelas públicas de Costa Rica, este análisis contempla las diferentes etapas del proceso de gestión de acuerdo a sus respectivas fases para lograr su implementación, así como, los diferentes aspectos internos y externos que favorecieron u obstaculizaron su desarrollo. La investigación es tipo cualitativa exploratoria, la cual consiste en estudio de caso de enfoque descriptivo. Entre sus resultados se destaca la necesidad de un cambio en la administración de la educación el proyecto y se sugiere un nuevo diseño que visualice la organización como una escuela versátil que responda a la actual Sociedad de la Información y Conocimiento (SIC) y a las Tecnologías de la Información y la Comunicación (TIC), desde una perspectiva colectiva y consensuada en la búsqueda de un centro educativo cada vez más innovador y mejorado.
\end{abstract}

Palabras clave.Sociedad de la información y el conocimiento (SIC), administración de la educación, proceso de gestión, tecnologías de la información y la comunicación (TIC), tecnologías móviles.

Abstract. The article summarizes the management of the National Project of Mobile Technology that has been implemented in pilot form by the Omar Dengo Foundation in three public schools in Costa Rica, contemplate the different stages of the management process in each of its phases to achieve its implementation, as well as the different internal and external aspects that favoured or hampered their development. This research is qualitative, descriptive and exploratory. Its results include the need for a change in the administration of education and suggest a new design which display the organization as a versatile school which responds to the current Society of Information and Knowledge (SIC) and the Information Technology and Communication (ICT), since a perspective collective and consensual in pursuit of an ever more innovative and better educational center.

Keywords. Society of Information and knowledge (SIC), management education, process management, Technologies of Information and Communication (TIC), and mobile technologies.

1 Máster en Ciencias de la Educación con énfasis en Administración Educativa de la Universidad de Costa Rica (UCR). Licenciada en Educación Primaria de la Universidad de Costa Rica (UCR). Ha laborado como docente en centros educativos públicos para el Ministerio de Educación Pública (MEP). También se ha desempeñado como docente y asistente de dirección en escuelas privadas y ha coordinado diferentes proyectos educativos en organizaciones no gubernamentales y en los centros educativos en que ha trabajado. Actualmente se desempeña como docente de primaria y universitaria. 


\section{Introducción}

Este artículo se enmarca en la necesidad del mundo postmoderno de responder a las tecnologías de la información y la comunicación (TIC), que está revolucionando la educación. Esta nueva forma de relación significa el comienzo de una nueva era de la información y la comunicación social que prevalece en la actualidad es denominada sociedad del conocimiento y la información (SIC), la cual permite un mayor acceso a los conocimientos, así como recibir y enviar mensajes en tiempo real a cualquier parte del mundo. Por eso, en educación son muchas las investigaciones alrededor del mundo que tienen como tópico este cambio en cuanto a los modelos de gestión pedagógica en los centros educativos, en parte por iniciativa de políticas de gobierno y también por iniciativa de profesionales gestores y educadores interesados por mejorar la calidad en sus centros educativos.

En la mayoría de estudios consultados se hace énfasis en los aspectos pedagógicos de las TIC, pero son muy pocos los que se orientan hacia la administración de la educación en este tipo de experiencias, sobre todo en Costa Rica, en vista de la reciente apertura para la implementación de las TIC en el aula surge la necesidad de ampliar la investigación en esta área.

Es de gran valor investigar el desarrollo de las experiencias obtenidas hasta ahora en relación con las TIC, desde un enfoque de gestión para rescatar el papel fundamental que tiene la persona directiva dentro del proceso para implementar este tipo de iniciativas en centros educativos, en cuanto a diferentes procesos como: la planificación, la organización, la coordinación, la dirección y la evaluación. Al conocer los procesos de gestión seguidos hasta el momento en las escuelas del estudio, se podrá identificar los aspectos que han favorecido o que han obstaculizado la gestión del proyecto. Para así, poder mejorar las próximas experiencias en futuras implementaciones.

Otro aspecto que no se puede ignorar, es el potencial que tiene, para un gestor de la educación, utilizar las TIC para potenciar la imagen del centro educativo, a partir de la participación de las redes sociales, uso de portátiles y la web en la institución. Al respecto, Francesc (2012) indica que la adopción de las soluciones tecnológicas en la educación no es un fin en sí mismo, su éxito depende de los usos pedagógicos que transforman la forma en que se enseña y se aprende en las aulas, con procesos más eficientes y atractivos para el personal docente y el estudiantado, lo cual provee un valor agregado a la educación.

Los aspectos antes mencionados nos indican un cambio en la concepción del centro educativo, de la educación, del estudiante y del docente en relación con las TIC. Esto significa tener en cuenta, que lo que una generación aprendía como relevante en el pasado, hoy puede haber perdido relevancia o necesitar adaptarse a lo nuevo. Esta situación genera la necesidad una enseñanza que desarrolle competencias en las personas, a fin de que estas 
puedan adaptarse a las nuevas demandas de la sociedad, ya sea en el desarrollo de un nuevo idioma, nueva habilidad o conocimiento tecnológico. Estas modificaciones requieren, también, de una transformación de la persona gestora de la educación, en cuanto a la apertura para realizar proyectos e innovaciones; el apoyo y dotaciones de materiales para su mantenimiento y crecimiento; así como en la visión a mediano y largo plazo de su institución educativa, para que pueda ser un gestor que permita el crecimiento positivo de todos sus miembros.

\section{Justificación del problema}

Las personas administradoras de la educación deben estar conscientes en cuanto su tarea en la educación, la cual consiste en la búsqueda del máximo desarrollo integral de todo ser humano. Esta optimización del comportamiento está determinada por el proceso educativo que reciba durante sus años de escolarización cada estudiante, y es desde la gestión de los centros educativos que se puede procurar establecer estrategias que faciliten el desarrollo de competencias a cada estudiante.

El desarrollo de estas habilidades en los educandos conlleva de parte de la persona gestora la capacidad de distinguir las verdaderas necesidades que posee cada uno de los alumnos. En los centros educativos se debe asegurar a las familias que sus hijos e hijas están recibiendo una educación pertinente con sus necesidades, esto porque según Glennane (2008), los padres:

Necesitan la seguridad de que los centros escolares o las aulas en las que sus hijos se encuentran ofrecen experiencias de aprendizaje que permitan de modo seguro el desarrollo de los alumnos para que lleguen a madurar y a poner en manifiesto sus mejores capacidades. (p. 164)

Ante esto, Ferraro (2012) indica que la organización educativa debe comprender el estudiante que llega a las aulas, el cual pretende obtener experiencias en el área tecnología. Los educandos forman parte de una generación de nativos digitales y para lograr atenderlos, el centro educativo en general, debe estar actualizado en esta temática. Por eso, la educación debe realizar un profundo análisis y una adaptación total al cambio tecnológico en la gestión de los centros escolares.

En estrecha relación, la administración de la educación será la clave para que, de manera paulatina, la educación se transforme con la aplicación de planes, programas y proyectos, que aspiren desarrollar las capacidades de los educados. De esta forma, la educación y las instituciones educativas responderán a verdaderas necesidades de la SIC, esto permitirá contribuir con el desarrollo de sus estudiantes, para que estos puedan enfrentar los retos actuales y futuros.

Por consiguiente, si desde la administración de la educación se desea alcanzar el máximo rendimiento del proceso educativo, se debe tomar en cuenta el desarrollo de las TIC en la realidad 
del centro educativo; orientando sus decisiones en la inserción, adaptación, capacitación e implementación de las TIC en el proceso de enseñar con nuevos y mejores métodos que faciliten a los estudiantes aprender de maneras más significativas y atractivas.

\section{Contextualización}

Para que una organización educativa responda a las necesidades de la SIC, se requiere de procesos complejos de innovación en diferentes aspectos de la educación. Algunas de ellas son mencionadas por Trahtemberg (2006), quien indica que estas son: el currículo, la pedagogía, la evaluación, la administración, la organización y el desarrollo profesional del profesorado, y la dirección.

Las TIC han revolucionado la educación en todo el mundo, cada vez son más las innovaciones que se implementan y el potencial de cambio es tan grande que, en ocasiones, es difícil predecir los impactos que puede traer a la educación. En el caso de las TIC varios estudios demuestran que pueden enriquecer la enseñanza, el aprendizaje y la gestión. Así, Hernández, Castro y Vega (2012), mencionan que el estudio y análisis de los procesos de integración y uso escolar de las TIC es una de las líneas relevantes en la investigación educativa de los últimos años, entre otras razones, porque la incorporación de las tecnologías digitales a las escuelas y aulas es una meta relevante de las políticas educativas en mayor parte de los gobiernos. En diferentes países la introducción de TIC en la educación ha sido un proceso complicado con diferentes facetas y ha estado lejos de ser una traducción directa de la política a la práctica. Ante esto, González (2011) señala que los problemas específicos se orientan a cuestiones como el garantizar la inversión en infraestructuras TIC, la formación inicial y permanente del profesorado, la creación de recursos TIC y la aplicación pedagógica de las TIC en el currículo.

Las personas administradoras de la educación deben estar conscientes de la principal tarea de la educación, la cual consiste en la búsqueda del máximo desarrollo integral de toda persona, desde la posición de Gento (1996), para esto se debe comprender que la educación supone:

Un proceso típicamente humano, llevado a cabo de forma intencional e integradora, para la optimización del comportamiento más conveniente a cada sujeto en su entorno propio, y determinado por la adquisición de conocimientos, la automatización de formas de actuación y la interiorización de actitudes que le otorgan valor en su conjunto y en sus peculiaridades. (p.67)

Esta optimización del comportamiento está determinada por el proceso educativo que reciba durante sus años de escolarización, y es desde la gestión de los centros educativos que se puede procurar establecer estrategias que faciliten el desarrollo de competencias a cada estudiante.

De esta forma, la educación busca desarrollar en los alumnos competencias para que sean capaces de resolver problemáticas y mejorar la calidad de vida. Por esta razón, toda persona 
que ocupe cargos directivos en educación debe contribuir para alcanzar esta meta máxima, muchas veces esto implicará realizar cambios para el beneficio del proceso en que se enseña y se aprende en los centros educativos.

Siendo evidente que las TIC son una herramienta eficaz para mejorar la calidad de la educación, es relevante analizar la gestión del Programa Nacional de Tecnologías Móviles en el Aula, para así comprender las políticas TIC que en Costa Rica se gestionan, para lograr el cambio tecnológico; cambios que se han venido dando desde hace unos años en otros países como Estados Unidos, Francia, España, Inglaterra, Finlandia, entre otros: en cuanto a la incorporación de las tecnologías móviles en el aula.

En Costa Rica, la obligación del Ministerio de Educación Pública de Costa Rica (MEP) con el desarrollo del Programa Nacional de Tecnologías Móviles en el Aula, se ha manifestado en algunos documentos como: El Proyecto Cerrando Brechas en Educación, Las Diez Líneas Estratégicas del Sector Educación y El Plan Nacional de Desarrollo, El Plan Nacional de Desarrollo de las Telecomunicaciones (PNDT); en cuanto a la implementación de la Estrategia Nacional de Banda Ancha y La Carta de Entendimiento MEP - SUTEL. En general estos documentos ponen en manifiesto el compromiso en el desarrollo de un país cada vez más tecnológico y establecen como uno de los pilares fundamentales el desarrollo de las TIC en la educación.

\section{Objetivos de la investigación}

En la presente investigación se analizó la gestión del Proyecto Nacional de Tecnología Móvil en el Aula, en tres centros educativos de la localidad de Heredia, donde se encuentra implementado en la actualidad de forma piloto una o dos aulas.

Este artículo responde a los siguientes objetivos específicos:

- Identificar los procesos de planificación llevados a cabo, en relación con el Proyecto Nacional de Tecnologías Móviles en el Aula, en tres centros educativos del circuito de Belén.

- Comprender el desarrollo de la organización del Proyecto Nacional de Tecnologías Móviles en el Aula en cada centro educativo.

- Describir los mecanismos de coordinación que dan en el Proyecto Nacional de Tecnologías Móviles en el Aula, entre las instituciones, Ministerio de Educación Pública y la Fundación Omar Dengo.

- Identificar la dirección que se da desde la administración del proyecto en cada centro educativo, en el Ministerio de Educación Pública y la Fundación Omar Dengo.

- Describir los procesos de evaluación, así como sus resultados, llevados a cabo por parte de los centros educativos, el Ministerio de Educación Pública y la Fundación Omar Dengo. 


\section{Marco conceptual}

\section{Las tecnologías de la Información y la comunicación (TIC)}

Es inevitable que las TIC sean parte de la vida de las personas, permitiendo que la humanidad entera pueda entrar en una comunicación universal, eliminando las distancias geográficas y construyendo nuevas formas de crear conocimiento colectivo. Esto, a pesar de lo difícil que pueda resultar permanecer actualizado a las nuevas tendencias del momento a nivel tecnológico, la educación tiene el reto principal de permanecer actualizada en cuanto a las necesidades de sus estudiantes, para que por medio de esta se pueda responder con la mayor eficacia.

En la misma línea Henao et. al. (2008), concluyeron que la forma en que se enseña y se aprende en las aulas debe estar en permanente revisión para incorporar la nueva tecnología en el sistema educativo. Esta revisión requiere ciertas competencias del personal que trabaja en el área educativa. Sobre todo porque requiere de la incorporación del personal docente y directivo, en la incorporación de los avances del siglo XXI en los centros educativos.

El simple uso de la tecnología trasciende la simple utilización de los aparatos para incluir el conocimiento, por la necesidad de construir y reelaborar las creencias, la información y los valores de una cultura particular así como el contexto social y personal. Por tanto, Pedreira (2003), señala que la tecnología ha determinado el medio de comunicación social que ha sido definitivo para la construcción de cada época histórica de la humanidad.

Según Morrissey (2009), algunos beneficios para los estudiantes al usar las TIC en la enseñanza y aprendizaje son:

Ofrecen entornos más ricos para aprender y tener experiencias, el uso de contenidos digitales, enriquece el aprendizaje, motivan y mantienen más activos a los estudiantes, admite la construcción de conocimiento mediante aprendizaje basado en proyecto, permite el trabajo grupal de manera más colaborativa, proporciona el acceso a recursos y a expertos que facilitan encuentros enriquecedores de aprendizaje, favorece que los estudiantes avancen a su propio ritmo de aprendizaje, las TIC permiten utilizar diferentes herramientas de evaluación e implica un reto o desafío para los estudiantes. (p. 84)

La comprensión de estos beneficios debe considerarse como un elemento favorecedor, para establecer estrategias de mejora en el proceso de enseñanza - aprendizaje en los centros educativos, por parte de las personas gestoras en colaboración con todo el personal del centro que busca una verdadera educación de mayor calidad. 


\section{TIC y centro educativo}

El aspecto más relevante es que existe un consenso mundial generalizado de las TIC deben integrarse en la vida de las escuelas. Considerando la actual necesidad de los infantes y adolescentes por utilizar herramientas que les permita el acceso a Internet. La publicación de la Organización de Cooperación y Desarrollo Económicos (OECD) durante el 2008, los países participantes confirman el rol central que tiene las TIC en el desarrollo de las economías basadas en conocimiento.

Para comprender mejor las diferencias entre la información y el conocimiento, se resume según Reyes (2000), las características propias de cada uno en la siguiente figura:

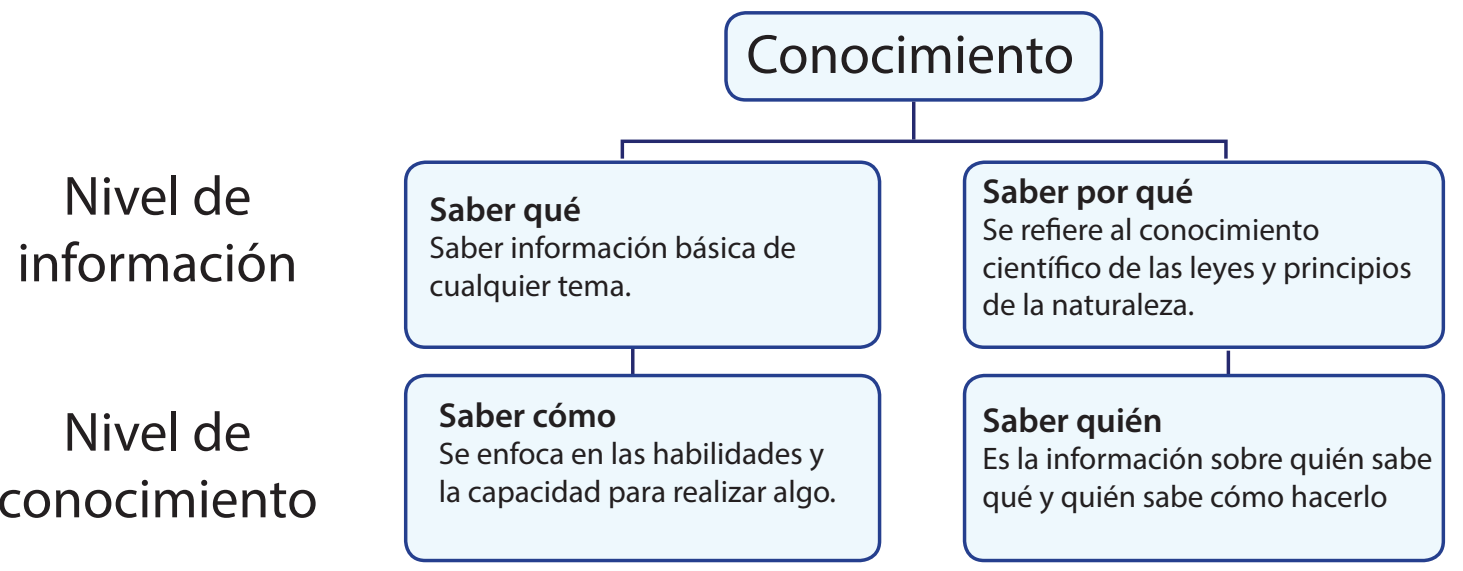

Figura 1. Características de la información y el conocimiento Nota: Adaptado de Reyes, 2000.

Se puede apreciar en la Figura 1, que el nivel de información se limita a la adquisición de información básica sobre una ley o principio de la naturaleza, a diferencia del nivel de conocimiento que se enfoca en desarrollar habilidades para usar esa información para resolver problemas o mejorar la calidad de vida.

\section{TIC y alumnado}

El concepto de alfabetización como tradicionalmente se ha entendido al proceso de aprender a leer y escribir, ha sido superado por nuevas concepciones de alfabetización que plantea la SIC. 
Esto a pesar de que la mayoría de las metas políticas de últimos años se han enfocado en mejorar la cobertura de la educación y optimizar los niveles de alfabetización tradicional. Hoy es claro que la posición de las naciones a escala mundial ha cambiado sus expectativas ante la alfabetización, enfocándose más a los aspectos de cobertura y acceso tecnológico.

Esta manera natural de las nuevas generaciones de acercarse e interactuar con las tecnologías es explicada por algunos autores como la teoría de los nativos digitales, ante esto la posición de Prensky (2009) es que viven la tecnología como parte de su entorno habitual, por eso la necesitan para satisfacer sus necesidades básicas, por eso Francesc (2006), señala la importancia de que la tecnología siempre esté disponible. Esto causa, sin duda, un cambio en la mentalidad de los estudiantes; la explicación de Lagos y Silva (2011) permite comprender mejor el cambio en las nuevas generaciones.

El haber crecido en un mundo digital de teléfonos celulares, computadoras, juegos de video, correo electrónico e Internet; tiene como correlato que cuando entran en el aula, donde lápices, papeles, libros y pruebas impresas son la norma; el cambio que experimentan les provoca desinterés en las actividades escolares. (p. 2)

Entonces, una escuela sin el acceso a la tecnología es incompatible con las necesidades educativas actuales. Esto implica, por parte de las personas encargadas de la educación, un cambio de mentalidad para poder responder a las verdaderas necesidades de las nuevas generaciones. Esto es lo que muchos autores señalan como alfabetización digital.

\section{La administración de la educación}

Desde esta perspectiva, la administración dela educación debe estaral servicio de la sociedad. Así, Arroyo (2008) la caracteriza como una actividad humana que tiene por objeto de estudio los sociosistemas que brindan el servicio educación. Por eso, en una organización educativa, la administración debe considerar múltiples elementos que varían de acuerdo con el contexto en el que se desarrollan y considerar lo cambiante de sus estructuras, tanto externas como internas; las cuales hacen que constantemente sea necesaria una adaptación de la estructura administrativa en función de las necesidades de las personas a las que presta el servicio.

Para lograr este cambio, la organización educativa debe realizar una revisión profunda. Específicamente, González (2011) menciona que esta revisión debe darse en cuanto a los objetivos, organización y prácticas de la escuela, desde lo macro a lo micro del sistema educativo.

El sistema educativo ha permanecido estable en cuanto a sus prácticas tradicionales desde tiempos atrás. Eso hace unos años fue motivo de alarma; sin embargo, las TIC han logrado evidenciar la necesidad de mejorar la forma en que se enseña en los centros educativos, tanto públicos como privados. 


\section{Proceso de gestión de los nuevos centros educativos}

La gestión puede considerarse un cuerpo organizado de principios y regularidades que explican el funcionamiento de las organizaciones, lo que se aplica para guiar y prescribir cómo han de funcionar y cómo han de ser gestadas con el propósito de que alcancen la mayor eficiencia y eficacia posibles (González, Nieto y Portela, 2003). La sociedad actual demanda que las organizaciones se replanteen los principios que, actualmente, guían la forma de gestionar; es decir, que éstas sean capaces de orientar sus acciones para cumplir con los objetivos primordiales, de manera que la organización pueda verdaderamente responder al momento actual de la sociedad.

La gestión moderna, en este sentido, debe estar orientada en innovar y diversificar su oferta pedagógica y administrativa. Para que, se pueda responder realmente a las necesidades actuales y ser un elemento que promueva el desarrollo y el cambio en la institución y en la comunidad, en general.

La gestión de la educación en el centro educativo, debería ser un conjunto articulado de acciones que promueva el logro de metas organizativas con el fin de lograr los objetivos contemplados en el plan organizativo institucional. Sin embargo, para que estas acciones logren ser eficientes deben estar planificadas intentando prever e identificar las estrategias necesarias para hacer realidad las metas propuestas.

\section{Planificación}

Este proceso de planificación debe estar sustentando las acciones en algún método, plan o lógica. Por su parte, Eyzaguirre (2006) comprende las siguientes fases de la planificación: "definir la misión y visión de la organización, establecer objetivos y metas, desarrollar supuestos acerca del entorno en que se desarrolla la organización, tomar decisiones respecto a las acciones a seguir, emprender las acciones elegidas y finalmente evaluar la retroalimentación del desempeño para volver a planificar" (p. 3). En resumen,establece el puente entre el punto donde se está y aquel otro donde se desea ir, indicando las formas de hacerlo.

Ninguna institución podría cumplir sus metas sin la clara visión de lo que desea alcanzar o a dónde quiere llegar. Se trata de buscar el enfoque o rumbo a seguir, para que de esta forma las acciones que tomen puedan orientar verdaderamente estos objetivos.

Las organizaciones deben tener un plan que responda a las expectativas sociales y políticas del momento. Además, el gestor debe desarrollar estrategias que tengan lógica de realización y permitan la participación de la mayoría de los actores de la organización. De la capacidad del gestor de concretar los planes, programas y proyectos, depende que las acciones que se 
desarrollen sean eficientes y eficaces. Permitiendo que todas las acciones que se planifiquen estén consensuadas colectivamente y con un claro enfoque hacia el cumplimiento de los objetivos educativos para mejorar la calidad de la educación de los estudiantes.

\section{Organización}

El término organizar se relaciona con la ejecución de todas las actividades humanas, las cuales para realizarse deben tener algún tipo de organización. Según Mintzberg, Quinny Voyer (1997), la organización es necesaria en la realización de tareas "(...) y hace necesarios dos requisitos fundamentales y opuestos entre sí: la división del trabajo en varias labores para su realización y el desempeño" (p. 161). Entonces, existe organización cuando se tiene claro el trabajo que se va a realizar y el desempeño que se espera de este.

Estaespecialización dela organización según Batemany Snell(2009),"consisteenlaadministración que une y coordina los recursos humanos, financieros, físicos y de información, entre otros, necesarios para alcanzar las metas" (p.20). Este proceso debe permitir asignar las personas a los puestos de trabajo para que hagan uso de los recursos necesarios para lograr los objetivos institucionales.

Se necesita una nueva forma de definir la distribución de tareas, comprendiendo esto de una forma más descentralizada y positiva, por eso ahora se necesita la autoorganización. Esto quiere decir que "se otorga mayor libertad a los miembros de organizaciones (como el empowerment), deberá acabar por llevarlos a alcanzar por sí mismos una nueva de integración" (Chiavenato, 2007, p.537). Esto requiere de una nueva estrategia organizacional que permita que sus miembros puedan actuar con mayor iniciativa, cooperación, creatividad y sinergia. El papel de la persona gestora será el de estimular estas actitudes, estableciendo un clima laboral que fomente el liderazgo y la innovación, además de asumir un papel de guía y de facilitador que acompañe el proceso que sus colaboradores realizan y dándoles el apoyo y recursos que necesitan.

\section{Coordinación}

En la ilustración del concepto, Fayol (1981) hacela comparación entreempresas coordinadas y aquellas que les falta coordinación. Un hecho presente en las organizaciones coordinadas es que, "en cada servicio, las divisiones y subdivisiones, son exactamente informadas sobre la parte que les corresponde en la obra común y sobre la ayuda mutua que deben prestarse"(p.226). Este proceso de coordinación se centra más en la especialización y en las obligaciones compartidas en una organización. Estas funciones se enfocaban en la tarea como la obra común.

En una institución educativa las acciones de sus diferentes miembros se caracterizan por ser complejas y muy variadas. Esto implica una nueva coordinación. La coordinación, según la Secretaría de Educación Pública mexicana (SEP, 2009), se puede orientar a las actividades de: 
(...) los docentes, estudiantes, padres de familia y otros agentes; así como el empleo de los recursos para desarrollar los procesos, programas y proyectos. Involucra la división del trabajo y de funciones a través de una jerarquía de autoridad y responsabilidad y un esquema de las relaciones entre los actores y su entorno. (p.59)

La coordinación es clave para el adecuado desarrollo de las actividades dentro de una organización educativa. En las interacciones de los diferentes actores se debe destacar el papel orientador de la persona gestora.

Desde esta perspectiva, la coordinación requiere un proceso reflexible de comunicación horizontal entre el directivo y su personal. Donde se favorezcan los aportes de todos los miembros de la organización y se establezcan estrategias para la división de responsabilidades y la supervisión de procesos con equidad.

Tienen gran importancia los mecanismos de coordinación. Mintzberg et al. (1997) explican los siguientes seis mecanismos de coordinación: "1) Adaptación Mutua; 2) Supervisión Directa; 3) Normalización o estandarización del proceso de trabajo; 4) Normalización o estandarización de los resultados; 5) Normalización o estandarización de los conocimientos y las habilidades o destrezas y 6) Estandarización de las normas" (p.161).

Estos mecanismos se pueden interpretar como: la necesidad de comunicarse entre las personas que realizan las tareas, las cuales necesitan de supervisión constante para hacer lo que debe hacerse, estandarizar la forma en que se hace, así como las metas por alcanzar, también estandarizar las habilidades para poder realizar sus responsabilidades y las normas o creencias que permiten la coordinación.

\section{Dirección}

La persona gestora debe movilizar a las personas; de acuerdo con Bateman y Snell (2009), esto significa que debe darles dirección y estímulo para que se desempeñen mejor. Dirigir "incluye motivación y la comunicación con empleados, individual o grupalmente, así como el contacto estrecho y cotidiano con las personas y la guía e inspiración hacia metas de equipo y de la organización" (p.20) Cuando se logra dar dirección a las acciones de las personas en una organización, la persona gestora debe invertir tiempo y esfuerzo en motivar a sus trabajadores y establecer dinámicas de comunicación sanas y productivas.

Así mismo, Bateman y Snell (2009)sugieren que esta función pretende orientar e influir en el comportamiento de las personas. Esta forma de orientación es la clave para que la organización sea la adecuada para cumplir los objetivos esperados. Si la persona gestora es capaz influir positivamente en el comportamiento de las personas puede lograr que muchas decisiones de sus colaboradores sean para beneficio de la organización. 
Es en este aspecto, donde el directivo debe asumir una posición estratégica. Siguiendo a Bateman y Snell (2009), es la dirección la que hace uso del liderazgo para que las personas contribuyan con sus ideas para enriquecer el trabajo en equipo de la organización, los resultados y la innovación. Esto asegura un proceso de cambio orientado hacia las metas colectivas.

Ante esto,Chiavenato (2007) indica que la dirección como proceso de dinamización de la organización debe cambiar su perspectiva tradicional y dar mayor valor a los aportes de los miembros de la organización. Principalmente destaca que la dirección debe "hacer que las cosas sucedan, servir al cliente, generar valor y producir y distribuir resultados relevantes para todos los involucrados" (p.537). Señala dos aspectos que deben permitir para la dinamización de la nueva dirección, son la redefinición del papel del gerente y la no concepción como guardián del espíritu de equipo corporativo.

El primer aspecto es abandonar la idea de que el gerente es el único que puede dirigir el futuro de la organización, considerando que miembros de la organización tienen un papel de liderazgo vital para el reajuste de las relaciones de poder de manera más horizontal. La dirección de la organización debe ser construida no por la persona gestora, sino por todos los miembros de la organización. Esta fortaleza brindará mayores resultados y dará mayor solidez a las metas que se desean alcanzar.

En segundo lugar, no son los gerentes los guardianes del espíritu de equipo corporativo. Chiavenato (2007) incluye que "la visión compartida de futuro, la conservación de la cultura organizacional y de las creencias y valores de la organización. Todo está cambiando" (p.537). Esto significa que el nuevo papel de la persona gestora es estimular las potencialidades de sus miembros, favoreciendo ambientes de aprendizaje y comunicación, para reestructurar constantemente el rumbo de la organización por medio de la negociación y el consenso.

\section{Evaluación}

Este proceso de control se orienta a la comprobación de la tarea, para mejorar los tiempos o mecanismos de elaboración del producto final. Sin embargo, en educación el logro educativo no es un material concreto sino abstracto.

Una escuela, desde el punto de vista de evaluación tradicional, es aquella que traslada a la escuela categorías de las instituciones empresariales y burocráticas, debe cumplir objetivos establecidos previamente. Una escuela con altos logros según SEP (2009), sería la que alcance sus objetivos.

Sin embargo, considerando la escuela como un escenario complejo se necesitan nuevos modelos evaluativos que permitan llevar acabo procesos evaluativos significativos para realidad educativa y social.

Por esto, Chiavenato (2007) señala que el control es uno de los que más ha tenido cambios en los tiempos. Enfocando las prácticas evaluativas más a favor de la libertad y la autonomía. En sí cambio de retroalimentación a realimentación. 
De acuerdo conRobbins y Coulter (2000), el proceso de control "es vigilar actividades para asegurarse de que se realicen de conformidad con lo planeado y para corregir cualquier desviación significativa" (p.12). Esto quiere decir, que se considera al control como un proceso de construcción del aprendizaje de la misma organización. El desarrollo del conocimiento que se genere de las experiencias de proyección, aplicación y evaluación deberían permitirle a la organización crecer y mejorar con el paso del tiempo.

Esto hace necesario de un proceso de evaluación o control más flexible. Capaz de interpretar las condiciones del contexto, la interacción de este con las organizaciones y las relaciones entre sus miembros. Ya que de la capacidad de dilucidar estas condiciones se permitirá la creación de propuestas de mejora más pertinentes.

\section{Metodología}

\section{Tipo de investigación}

El proceso y el diseño de esta investigación son cualitativos, porque según Rodríguez, Gil y García (1996) emerge de la reflexión del investigador tras sus primeras aproximaciones a la realidad objeto del estudio. Además, considerando la información suministrada por las investigaciones mencionadas en el estado del arte, el presente trabajo tiene un alcance de tipo exploratorio; de acuerdo con esto, Hernández, Fernández y Baptista (2010), mencionan "se realiza cuando el objetivo es examinar un tema o problema de investigación poco estudiado, del cual se tienen muchas dudas o no se ha abordado antes" (p.79).

Debido a que la búsqueda de investigaciones relacionadas con la gestión de tecnologías móviles en el ámbito escolar arrojó pocos resultados, este campo de estudios puede considerarse como poco estudiado, existiendo muchas líneas de investigación que se pueden desarrollar; es por esta razón que el estudio aquí planteado se considera de tipo exploratorio.

Además, será un estudio de caso con enfoque descriptivo como lo menciona Hernández et. al. (2010), "Ios estudios descriptivos buscan especificar las propiedades, las características y los perfiles importantes de personas, grupos comunidades o cualquier otro fenómeno que es sometido a un análisis" (p.80). Este estudio está caracterizado por ser de tipo exploratorio con enfoque descriptivo, pues busca describir la gestión del programa de tecnologías móviles en los centros educativos de la muestra del cantón de Belén.

\section{Población}

De un universo de doce centros, se escogieron tres centros educativos que participan del Programa Nacional de Tecnologías Móviles en el Aula. A los centros educativos participantes en 
esta investigación, se les asignó la siguiente nomenclatura: \# 1 Escuela Fidel Chaves, \# 2, Escuela España y \# 3 Escuela Manuel del Pilar Zumbado.

Para definir la población, Barrantes (2010), la establece como el conjunto de elementos que tiene una característica común. Por lo tanto, para la investigación se considera población a los siguientes actores: director(a) del programa, el asesor del programa, los directivos de cada centro educativo, así como los docentes participantes de las diferentes instituciones.

\section{Fuentes de información.}

Las fuentes de información se clasifican en dos: las primarias y secundarias.

Las fuentes primarias de esta investigación son las personas en cargos directivos en relación con el programa, los asesores, coordinadores, los directivos de las escuelas y los docentes participantes y no participantes del programa.

Las fuentes secundarias fueron: libros, artículos científicos (nacionales e internacionales), trabajos finales de graduación, así como documentos relacionados con el desarrollo del Programa de Tecnologías Móviles en el Aula.

\section{Métodos y análisis de los datos.}

Este estudio se fundamenta en la matriz paradigmática cualitativa; las técnicas cualitativas por utilizar se relacionan con el método seleccionado, así como con el tema o pregunta generadora del estudio (Gurdián, 2007). Los métodos que se utilizan son: observación, entrevista y revisión de documentos.

Todos los investigadores desarrollan sus propios modos de analizar los datos cualitativos. El análisis de los datos es proceso dinámico y creativo, a lo largo del análisis se trata de obtener una comprensión más profunda de lo que se ha estudiado, y se continúan refinando las interpretaciones. El análisis de datos, implica ciertas etapas diferenciadas. Durante las cuales se contará con apoyo de la herramienta digital Atlas.ti 5, la cual consiste en un software especializado para facilitar el análisis de datos cualitativos.

Estas etapas seguidas en análisis son propuestas por Rojas (2008):

Transcripción y lectura de cada entrevista delimitando y subrayando los fragmentos textuales y al margen se hacen anotaciones (códigos), luego de la codificación de cada una de las transcripciones se produce a juntar todos los fragmentos de una misma sección, reclasificar e interpretar el material y abrir subsecciones si fuera necesario "integración local" (bajo categorías descriptivas o conceptuales relacionadas con la cuestión) y organizar todas las secciones de manera coherente de acuerdo con una línea o secuencia argumental narrativa, explicativa, "integración inclusiva". (p. 97) 


\section{Codificación, organización de los datos y triangulación.}

En la investigación cualitativa la codificación es un modo sistemático de desarrollar y refinar las interpretaciones de los datos. El proceso de codificación incluye la reunión y análisis de todos los datos que se refieren a temas, ideas, conceptos interpretaciones y proposiciones.

La fase del análisis cualitativo consiste en lo que Rojas (2008) indica como integración inclusiva, lo cual trata de interpretar los datos en relación con el contexto en que fueron recogidos.

Este proceso consistió en recoger y analizar datos desde distintos ángulos para compararlos y contrastarlos entre sí. En este caso, la triangulación será desde la información obtenida con los instrumentos en el trabajo de campo. Una vez obtenidos los resultados de la investigación, se contrastaran con la teoría para producir una discusión a luz de la información de los autores, para así lograr determinar las conclusiones del análisis.

\section{Análisis y resultados}

Para el análisis se establecieron cinco categorías con sus respectivos indicadores de cada una de las temáticas anteriores, las cuales se ilustran en la Figura 2. El color de cada uno representa la categoría en el avance del análisis.

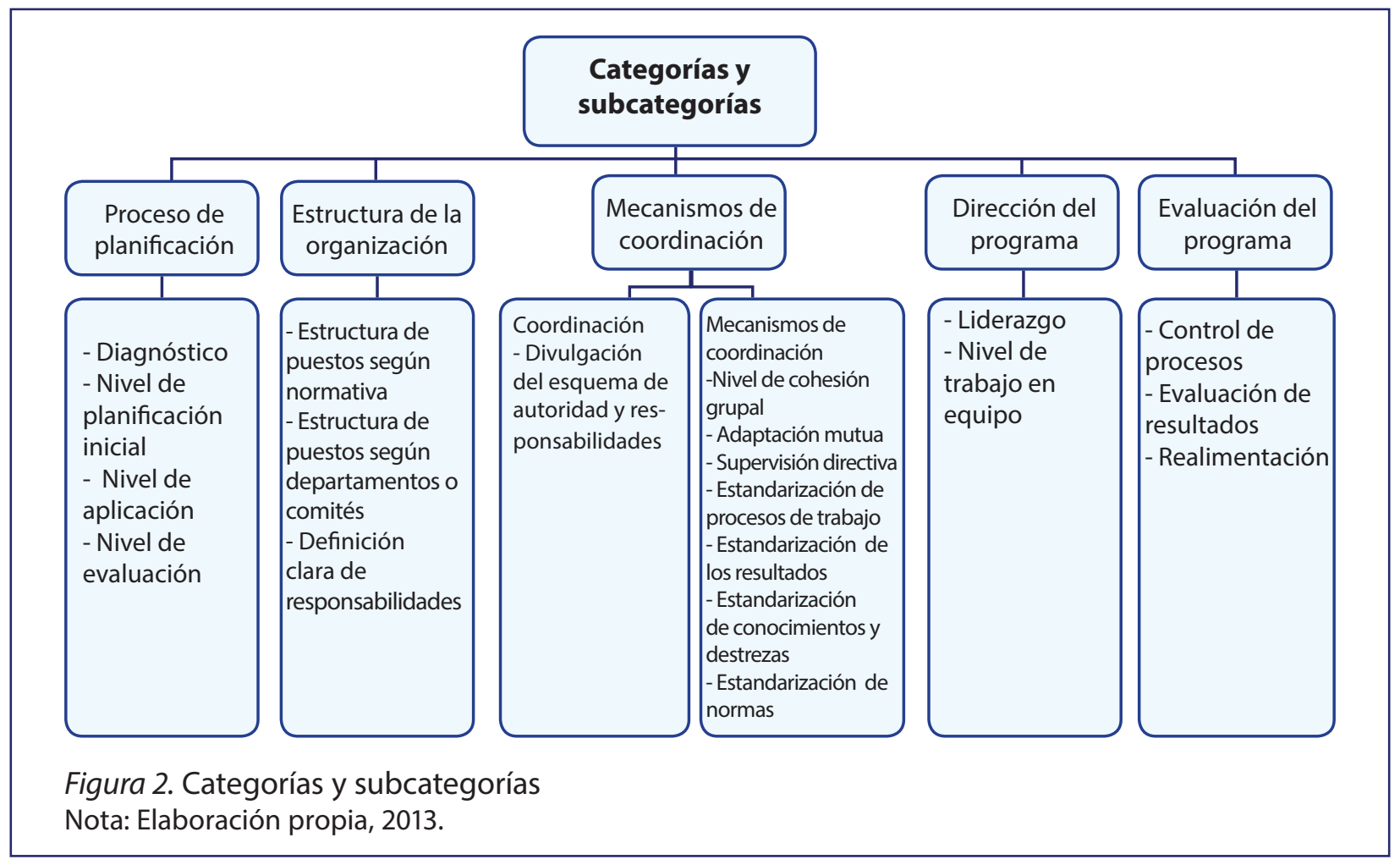

Nota: Elaboración propia, 2013. 


\section{Procesos de planificación llevados a cabo en relación con el Programa Nacional de Tecnologías Móviles en el aula en las tres escuelas}

En este primer paso, se establece el puente entre el punto donde se está y aquel otro donde se desea ir, indicando las formas de hacerlo. Por esta razón, la temática del proceso de planificación se dividió en las siguientes categorías: diagnóstico, nivel de planificación inicial, nivel de aplicación y nivel de evaluación.

\section{Diagnóstico.}

A continuación, en la Tabla 1, se resume a nivel general, la información recopilada en las entrevistas a profundidad en cada una de las instituciones implicadas.

Tabla 1

Extracto de la información recopilada sobre el diagnóstico

\begin{tabular}{lll}
\hline Institución & \multicolumn{1}{c}{ Diagnóstico } & \multicolumn{1}{c}{ Opiniones expresadas } \\
\hline 1 & $\begin{array}{l}\text { En los tres centros educativos } \\
\text { hizo falta la recolección de datos } \\
\text { relativos a las dimensiones de } \\
\text { contexto y de entrada del diag- } \\
\text { nóstico. }\end{array}$ & $\begin{array}{l}\text { Director: fue un poco complicado, porque cuando ellos me plantean el } \\
\text { zromecto de trabajo en el aula, o sea, no había nada y nosotros lo empe- } \\
\text { zirector: ingresé a la institución en el 2010. Entonces, a partir de ese } \\
\text { momento puedo dar fe. }\end{array}$ \\
3 & & $\begin{array}{l}\text { Director: en programa inicio cuanto los de la FOD empezaron donando } \\
\text { los computadores y la red inalámbrica. }\end{array}$ \\
\hline FOD - MEP & $\begin{array}{l}\text { No recopilaron información para } \\
\text { el diagnóstico. }\end{array}$ & $\begin{array}{l}\text { En momento que empezaron con el programa yo todavía no trabaja } \\
\text { con la Fundación Omar Dengo. }\end{array}$ \\
\hline
\end{tabular}

Nota: Entrevistas a profundidad a los directores de los tres centros educativos, 2013.

El personal de las tres escuelas consultadas no tienen conocimiento de diagnóstico inicial. Esto significa que hizo falta la recolección de datos relativos a las dimensiones de contexto y de entrada, para asegurar los procesos de apertura y búsqueda de compromiso del centro educativo y comunidad en un proceso inicial, lo cual es clave para alcanzar una participación efectiva.

\section{Nivel de planificación inicial.}

El nivel de planificación inicial se resume en la Tabla 2, en ella se abrevia el proceso en el cual se redactó el documento de la propuesta pedagógica de tecnología móvil. 
Tabla 2

Proceso de planificación inicial en los centros educativos

\begin{tabular}{lll}
\hline Institución & \multicolumn{1}{c}{ Planificación inicial } & \multicolumn{1}{c}{ Opiniones expresadas } \\
\hline 1 & $\begin{array}{l}\text { La FOD envió una persona para que redactara el } \\
\text { plan que estaba ya en ejecución. }\end{array}$ & $\begin{array}{l}\text { Se visualiza hacia la implementación de esa propues- } \\
\text { ta pedagógica en todo en el centro educativo. }\end{array}$ \\
\hline 2 & $\begin{array}{l}\text { La FOD realizó la redacción del plan, que consistió } \\
\text { en una propuesta pedagógica para implementar } \\
\text { de tecnología móvil en el aula. }\end{array}$ & $\begin{array}{l}\text { El programa se implementó con el plan ya redactado } \\
\text { por la FOD. }\end{array}$ \\
\hline FOD - MEP & $\begin{array}{l}\text { Se hizo una alianza entre la FOD y el MEP para } \\
\text { luego dirigir esos equipos de trabajo y hacer una } \\
\text { propuesta pedagógica para las escuelas que se } \\
\text { seleccionarán. }\end{array}$ & $\begin{array}{l}\text { En Costa Rica no había una propuesta en cuanto a } \\
\text { el proyecto una vez redactado hubo que proponerlo } \\
\text { a los directores y asesores. }\end{array}$ \\
\hline
\end{tabular}

Nota: Entrevistas a profundidad al asesor de tecnología móvil de la FOD, 2013.

Una vez que el programa estaba implementado en la primera escuela, surgió el interés por parte de la FOD y el MEP para redactar un documento que resumiera el plan piloto que se estaba ejecutando. El documento que se redactó por la FOD con apoyo de la docente \# 1 consistió en una propuesta pedagógica que orientaba al docente para que implementara las Classmate PC en el aula. Esto significa, que este escrito no era un plan para gestionar el programa de tecnología móvil y por lo tanto dejó muchos aspectos importantes desde la posición de la administración de la educación deben retomarse para asegurar el futuro del programa en cada institución.

\section{Nivel de aplicación.}

El proceso de aplicación debe considerar la preparación tanto de las familias, como de los estudiantes y docentes implicados en el proyecto. En la Tabla 3 se puede observar la reacción de las familias ante este aspecto.

Tabla 3

Reacción de las familias ante la implementación del programa

\begin{tabular}{lll}
\hline Institución & \multicolumn{1}{c}{ Nivel de aplicación } & \multicolumn{1}{c}{ Opiniones expresadas } \\
\hline 1 & $\begin{array}{l}\text { En la escuela \#1 se realizó una } \\
\text { inducción a los docentes, familias } \\
\text { y alumnos. }\end{array}$ & $\begin{array}{l}\text { Docente \#1: Al principio tuve problemas también con los padres, cuan- } \\
\text { do yo planteé la idea, pero todo cambió cuando vieron los frutos. }\end{array}$ \\
\hline 2 & $\begin{array}{l}\text { En las escuelas \#2 y \#3 la inducción } \\
\text { con las familias en la reunión de } \\
\text { padres. }\end{array}$ & $\begin{array}{l}\text { Director \#2: Algunos padres reaccionaron bien y otros de forma nega- } \\
\text { tiva. Incluso una familia decidió sacar a la niña de la escuela. }\end{array}$ \\
& $\begin{array}{l}\text { Docente \#3: Al principio las familias no entendían bien de que se trata- } \\
\text { ba, pero después ayudaron mucho. }\end{array}$ \\
\hline
\end{tabular}

Nota: Entrevistas a profundidad a los directores y docentes de los centros educativos, 2013. 
En la escuela \# 1 se realizó una inducción a los docentes, padres y alumnos. Por eso, en ese centro educativo el proceso posterior a la inducción fue más claro para todos los interesados. Ocurrió lo contrario en las escuelas \# 2 y \# 3, los docentes no tuvieron el mismo apoyo para realizar la inducción. En relación con la inducción, es la persona directiva quien debe asegurar que cada año se realice un proceso clave para que los padres sean tomados en cuenta y participen activamente del desarrollo del programa.

Algunos recursos fueron mencionados como necesarios en el nivel de aplicación se indican en la Tabla 4.

Tabla 4

Recursos necesarios para el programa de tecnologías móviles

\begin{tabular}{ll}
\hline \multicolumn{1}{c}{ Recursos necesarios } & \multicolumn{1}{c}{ Opiniones expresadas por las docentes } \\
\hline Dotación de infraestructura & $\begin{array}{l}\text { Necesidad de mejorar las conexiones eléctricas para poder cargar las computadoras en } \\
\text { la noche, la elaboración de un mueble especial para poder guardar de manera segura las } \\
\text { laptops, la necesidad de adquirir unos pupitres para los estudiantes que sean adaptables } \\
\text { al uso del equipo, la adquisición de adaptadores, regletas y la instalaciones de ventilación } \\
\text { y una mejor iluminación. }\end{array}$ \\
\hline $\begin{array}{l}\text { Recursos informáticos míni- } \\
\text { mos }\end{array}$ & Las computadoras classmate PC, la Internet y un proyector exclusivo para el programa. \\
\hline $\begin{array}{l}\text { La formación del profeso- } \\
\text { rado }\end{array}$ & No existió ningún tipo de formación previa para los docentes \\
\hline $\begin{array}{l}\text { Predisposición favorable } \\
\text { hacia las nuevas tecnologías }\end{array}$ & $\begin{array}{l}\text { Existía mucho temor hacia las computadoras por parte del cuerpo docente, sobre todo } \\
\text { por el reto que implicaba planear y realizar las lecciones utilizando el equipo. }\end{array}$ \\
\hline $\begin{array}{l}\text { Disposición de materiales de } \\
\text { naturaleza digital }\end{array}$ & $\begin{array}{l}\text { Al inicio era muy poco el material que conocía, por eso se le complicaba mucho planear } \\
\text { las clases y tardaba mucho tiempo pensando cómo utilizar las herramientas de las compu- } \\
\text { tadoras. }\end{array}$ \\
\hline $\begin{array}{l}\text { La configuración de equipos } \\
\text { externos de apoyo al profe- } \\
\text { sorado }\end{array}$ & $\begin{array}{l}\text { El equipo externo apoyó a los tres centros educativos fue el de la FOD. Principalmente el } \\
\text { asesor del Tecnologías Móviles, el técnico y los asesores del MEP tanto de materias básicas } \\
\text { como de evaluación. }\end{array}$ \\
\hline
\end{tabular}

Nota: Adaptado de Área (2002) y entrevistas a profundidad a los directores y docentes de los centros educativos, 2013.

En el plan del programa se debió impulsar la dotación de infraestructura, los recursos informáticos mínimos, la formación del profesorado y la predisposición favorable hacia las nuevas tecnologías del cuerpo docente, la disponibilidad de materiales didácticos o curriculares de naturaleza digital y la configuración de equipos externos de apoyo al profesorado. Sin embargo, al no existir claridad en la planificación por parte del gestor estos aspectos no fueron asumidos por la organización, sino que fueron resueltos en parte por la persona docente o por la FOD. 


\section{Nivel de evaluación}

En la Figura 3, se resumen los logros obtenidos por el programa en los diferentes agentes implicados en el proceso.

Alumnado
1. Estudiantes motivados y
comprometidos con el estudio.
2. Cambio positivo en la disciplina.
3. Aprendizajes duraredos.
4. Estudiantes que se atreven a
cuestionar.
5. Quieren ir más allá del contenido
mismo.
6. Comprensión de temas difíciles.
7. Desarrollo en destrezas
tecnológicas.
8. Deseo de hacer las cosas
diferentes.
9. Desarrollo de su creatividad.
10. Trabajo en equipo y respeto.
11. Autoestima: Superan la timidez.
12. Habilidad en la resolución de
problemas.
problemas.

\section{Docentes}

1. Mayor motivación.

2. Mayor creatividad a la hora de impartir las clases.

3. Le encontramos sentido a la incorportación de la tecnología al curriculum.

4. Correlacionar las áreas hace el trabajo más eficiente y clases más dinámicas.

5. Correlacionar con artes plásticas permite trabajar algunos temas en forma concreta.

6. Se logra mayor aprendizaje por parte de los estudiantes, se refleja en el redimiento académico.

7. Desarrollo de destrezas en el uso de las computadoras y sus programas.

8. Mayor acercamiento con los estudiantes y colegas.

9. El planeamiento ha variado, se refleja la integración como un recurso de apoyo para el desarrollo de temas.

10. Mayor disciplina, hay más control con el grupo.

11. Trabajo más práctico y productivo.

\section{Padres de familia}

Han manifestado que sus hijos(as):

1. Se muestran más motivados para asistir a la escuela.

2. Han mejorado sus notas.

3. Demuestran haber aprendido más.

4. Recuerdan más lo que aprenden.

5. Se interesan más en sus trabajos.

6. A veces llegan a la casa a experimentar lo que hizo en la escuela.

7. Involucran más a su familia en lo que aprende.

8. Demuestran más opiniones respecto de las cosas.

9. Son más autónomos para estudiar.

10. Usa más la computadora en sus trabajos.

Figura3. Logros de la evaluación inicial según la FOD

Nota: Adaptado de Cubero, 2008a.

Estos logros muestran, desde la perspectiva de la FOD, una reacción positiva de parte del alumnado, el personal docente participante así como de los padres de familia hacia el programa en ejecución. Se denota que todos los interesados desean aprender de una forma innovadora la cual les permita mejorar la calidad de la educación. 


\section{La organización.}

Este segundo paso en la organización del programa, permite comprender la importancia de realizar las actividades propuestas y el papel de los responsables de estas. Se debe destacar la relevancia de distribuir las funciones a los integrantes del equipo de trabajo y asegurarse que cada uno comprenda sus responsabilidades y lo que desea alcanzar la organización con su trabajo. Por eso, se analizaron en dos categorías: la estructura de puestos y equipos de trabajo.

Estructura de puestos y equipos de trabajo.

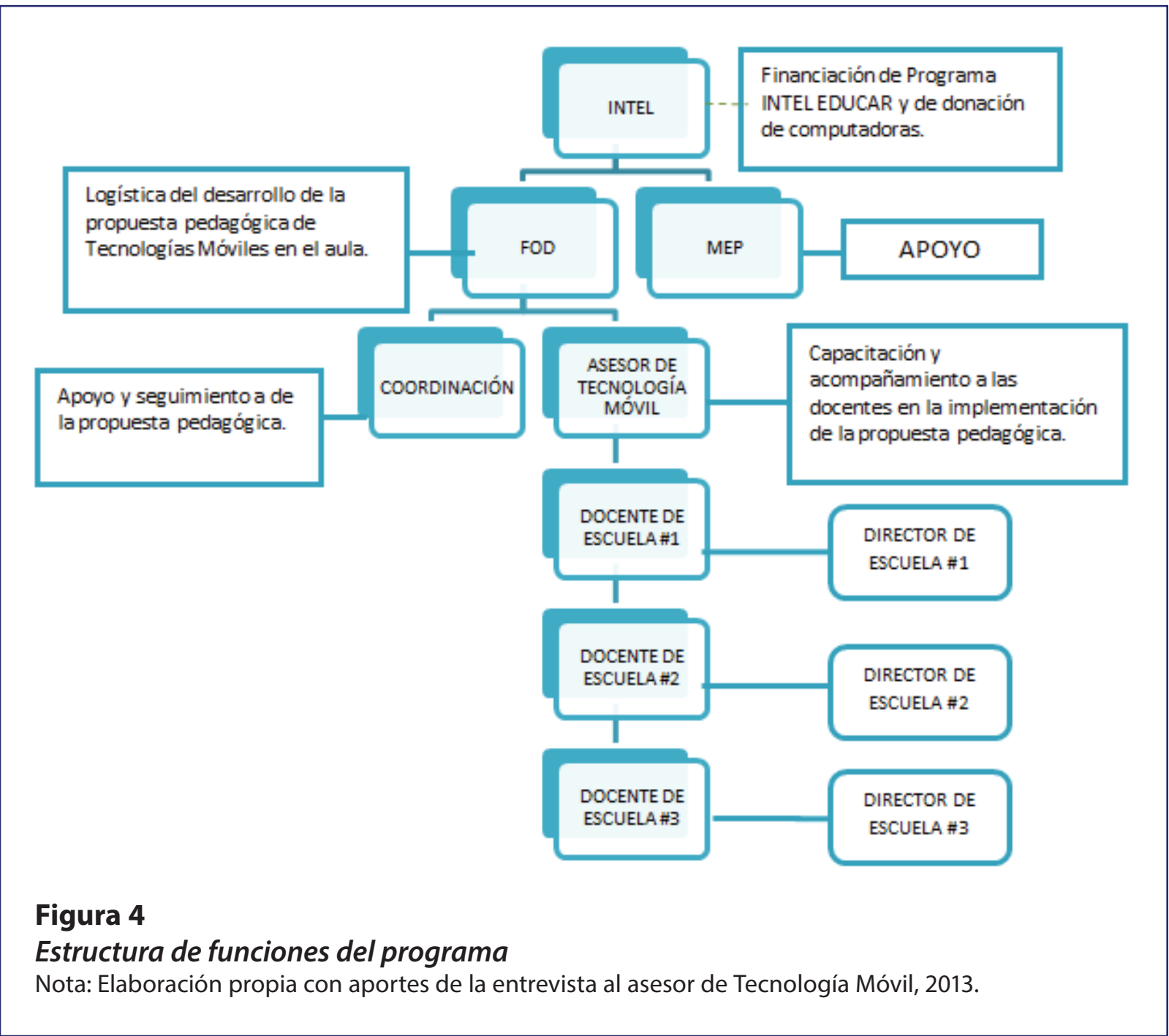


En la Figura 4, se puede inferir que INTEL y la FOD tienen un interés especial en desarrollar la propuesta pedagógica; posteriormente, el MEP participa y brinda una alianza y apoyo para que esta propuesta pueda implementarse en estos centros educativos. La persona en la coordinación tenía a su cargo todos los programas de INTEL EDUCAR, con apoyo financiero de INTEL; entre estos programas se encontraba el de tecnología móvil. La persona asesora se encarga de redactar la propuesta, realizar la capacitación y dar el acompañamiento a las escuelas participantes; que en total eran 11 centros. El personal docente es el encargado de ejecutar la propuesta pedagógica en sus salones de clase con el aval de la persona directiva.

Tabla 5

Asignaciones de diferentes integrantes del programa tecnologías móviles

\begin{tabular}{|c|c|}
\hline Estructura de puestos & Opiniones expresadas \\
\hline INTEL & $\begin{array}{l}\text { Coordinación del PRONIE: Financiación de Programa INTEL EDUCAR y de donación de compu- } \\
\text { tadoras. }\end{array}$ \\
\hline FOD & $\begin{array}{l}\text { Asesor: Logística para que la propuesta pedagógica de Tecnología Móvil de se redactara e } \\
\text { implementara de forma piloto. Docentes: Encargados de traer las computadoras, de realizar las } \\
\text { capacitaciones y brindar la asesoría para que la propuesta pedagógica se lograra implementar. }\end{array}$ \\
\hline MEP & Docentes: se indica que no comprenden bien el papel que tiene dentro del programa. \\
\hline $\begin{array}{l}\text { COORDINACIÓN DE } \\
\text { INTEL EDUCAR - PRONIE }\end{array}$ & $\begin{array}{l}\text { Asesor: donación de computadoras móviles en escuelas multigrado y unidocentes, además de } \\
\text { la implementación y la capacitación }\end{array}$ \\
\hline $\begin{array}{l}\text { ASESOR DE } \\
\text { TECNOLOGÍA MÓVIL }\end{array}$ & $\begin{array}{l}\text { Asesor: asesoraba al docente a poner en práctica otras metodologías de tecnologías móviles } \\
\text { propuestas por la FOD. }\end{array}$ \\
\hline DIRECTOR & $\begin{array}{l}\text { Docentes: persona gestora que toma las decisiones que tienen implicaciones en cuanto a } \\
\text { aspectos administrativos, recurso humano, financiero, físico y de información, en el centro edu- } \\
\text { cativo. }\end{array}$ \\
\hline DOCENTE & $\begin{array}{l}\text { Directores: se han responsabilizado de guardar las computadoras en sus aulas, de utilizarlas } \\
\text { según los lineamientos dados por la FOD, así como de tomar en cuenta los aspectos relevantes } \\
\text { del planeamiento, evaluación y metodología del modelo } 1 \text { a } 1 \text { en sus aulas. Adicionalmente se } \\
\text { han ocupado de coordinar con otros docentes el uso de las máquinas. }\end{array}$ \\
\hline
\end{tabular}

Nota: Entrevistas a profundidad a los directores, docentes de los centros educativos y funcionarios del MEP y FOD, 2013.

En general, tomando en cuenta el potencial tan grande que tiene este programa y los recursos con los contaba y cuenta, no se ha realizado una organización que fomente el logro más allá de los aspectos pedagógicos del aula que cada docente realiza con la propuesta. Es importante comprender que la organización debe mejorar los aspectos de división de trabajo, asignación de funciones y el trabajo en equipo. 


\section{Coordinación}

De la categoría mecanismos de coordinación, se analizarán inicialmente los siguientes indicadores de la coordinación: la divulgación del esquema de autoridad y responsabilidades del programa; y luego la categoría de mecanismos de coordinación.

\section{Divulgación del esquema de autoridad y responsabilidades del programa}

La divulgación del esquema de autoridad y de las funciones de los participantes del programa, no se ha hecho en forma explícita en ningún documento o reunión, según los participantes. En las tres escuelas se indica que existe comunicación en relación con el programa por parte de la FOD a través de un asesor de Tecnología Móvil, que se encarga de visitar, orientar y capacitar a los docentes participantes, esta dinámica se ilustra en la Figura 5. Así mismo, en el centro educativo la persona directiva es la que asume la gestión todo el aspecto en relación con el proyecto y el profesorado desarrolla los aspectos pedagógicos que se dan en el aula. Sin embargo, la relación con el MEP enfatiza el no tener claro el esquema de autoridad ni las funciones del programa.

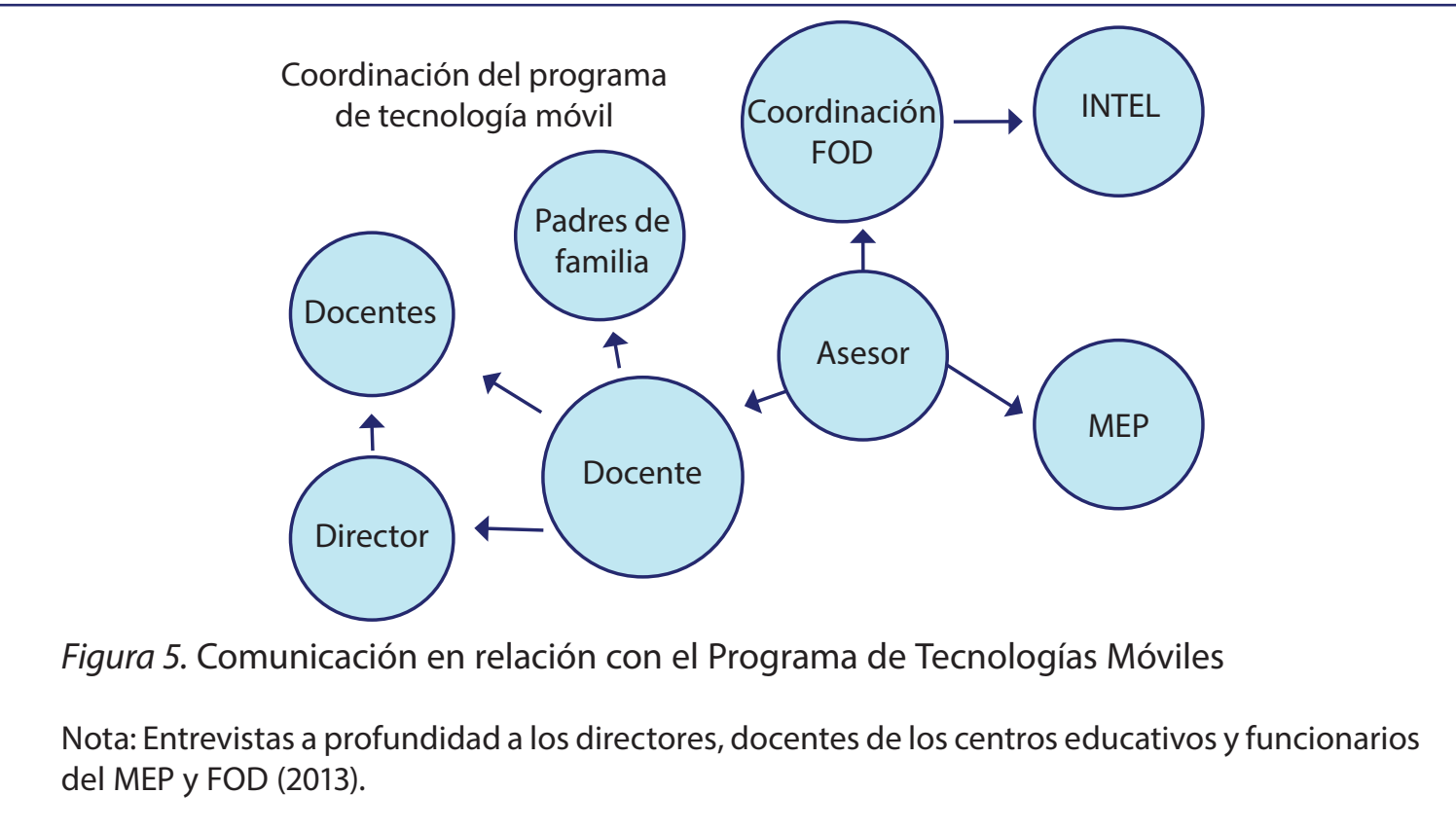

Además, el director del centro educativo \# 1 , enfatiza que al inicio del proyecto se desarrollaba en coordinación directa del centro educativo \# 1 con INTEL, y que luego se logró empezar con el MEP y la FOD. Por eso, este centro educativo se ha empoderado de los procesos 
en lo que se refiere al programa de una forma tan fuerte. Incluso la docente que ha participado desde su inicio, en el 2005, ha tenido que compartir su experiencia con otras docentes de Costa Rica y otros países. Esto muestra la verdadera importancia de la experiencia y la necesidad de documentar el papel que se ha asumido de la dirección del proyecto hasta el desarrollo de los procesos pedagógicos en el aula.

\section{Mecanismos de coordinación}

\section{Nivel de cohesión grupal}

En general, se puede desarrollar una visión que motive a todo el personal a buscar la innovación, pero esto requiere de esfuerzo, espacios para comunicarse y la creación de estrategias especificas que pueden responder a las problemáticas de forma más permanente y colectiva.

\section{Adaptación mutua}

En las tres escuelas ha existido una buena adaptación mutua con las asesorías de la FOD, asimismo en relación con las asesorías del MEP, las escuelas \# 1 y \# 2 mantuvieron una fluida comunicación con las asesorías de primaria y evaluación. En cuanto al MEP y la FOD, hace falta que se establezcan mecanismos que favorezcan mejorar la disposición y la fluidez de comunicación entre las entidades en procura del establecimiento de alianzas estratégicas para la mejorar el programa.

\section{Supervisión directiva}

Entonces, la supervisión directiva del programa debería conocer lo que realizan los docentes, para orientar, ayudar y estimularlos para mejorar la dinámica de funcionamiento en la organización. Desde esta posición, en dicha categoría se analizan los siguientes indicadores: asignación de funciones y responsabilidades, y el monitoreo explícito de las funciones.

En el centro educativo \# 1, es la persona directiva la encargada de monitorear el proyecto y acompañar al docente que está trabajando desde el 2006. Aunque, este monitoreo se llevaba a cabo con mayor frecuencia en sus inicio.

En la escuela \# 2 el monitoreo no se ha realizado en relación con el programa, y en la escuela \# 3 este proceso se ha realizado de forma horizontal con mucha realimentación con la persona docente.

El papel del asesor de la FOD ha sido clave en el proceso de monitoreo de las escuelas, porque ha sido una persona que brinda conocimiento, sugerencias, ayudas, entre otras cosas, que han permitido que se mantenga el interés y el deseo de seguir aprendiendo y mejorando en el proyecto de tecnología móvil. 
En síntesis, el proceso de monitoreo se ha realizado con mayor vigencia en las escuelas \# 1 y \# 3, debido a que las personas gestoras han tenido mayor apertura para conocer el programa y se comunican fluidamente con las personas docentes que participan en él.

\section{Estandarización de procesos de trabajo}

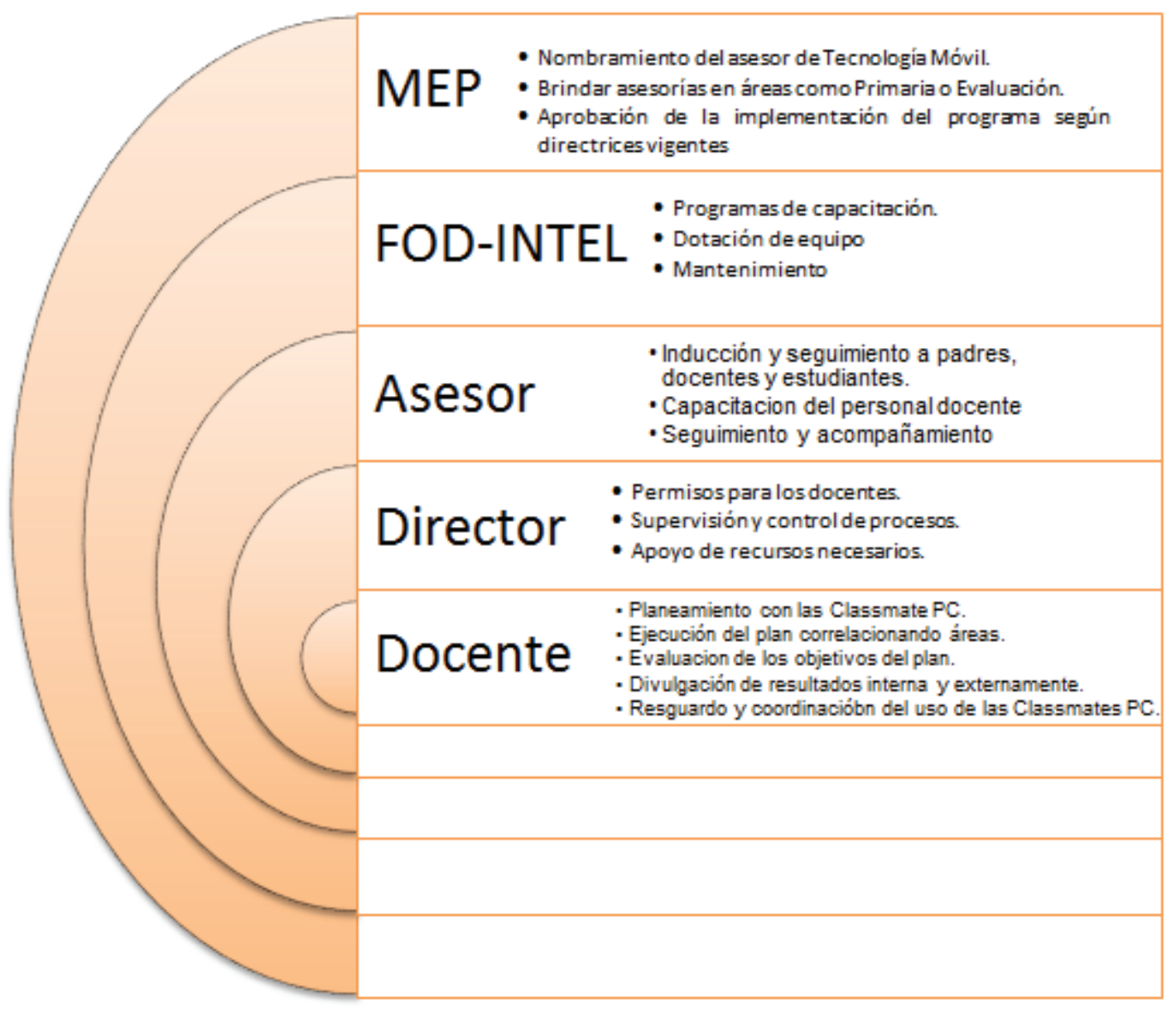

Figura 6. Proceso de uniformidad del trabajo en los centros educativos del programa

Nota: Entrevistas a profundidad a docentes y directores de los centros educativos, funcionario de la FOD y MEP, 2013. 
En suma, los tres centros educativos han recibido la información necesaria para uniformar de procesos de trabajo. Sin embargo, el trabajo que se realiza en cada centro depende del rol que asuma cada una de las personas responsables de cada tarea.

\section{Estandarización de los resultados}

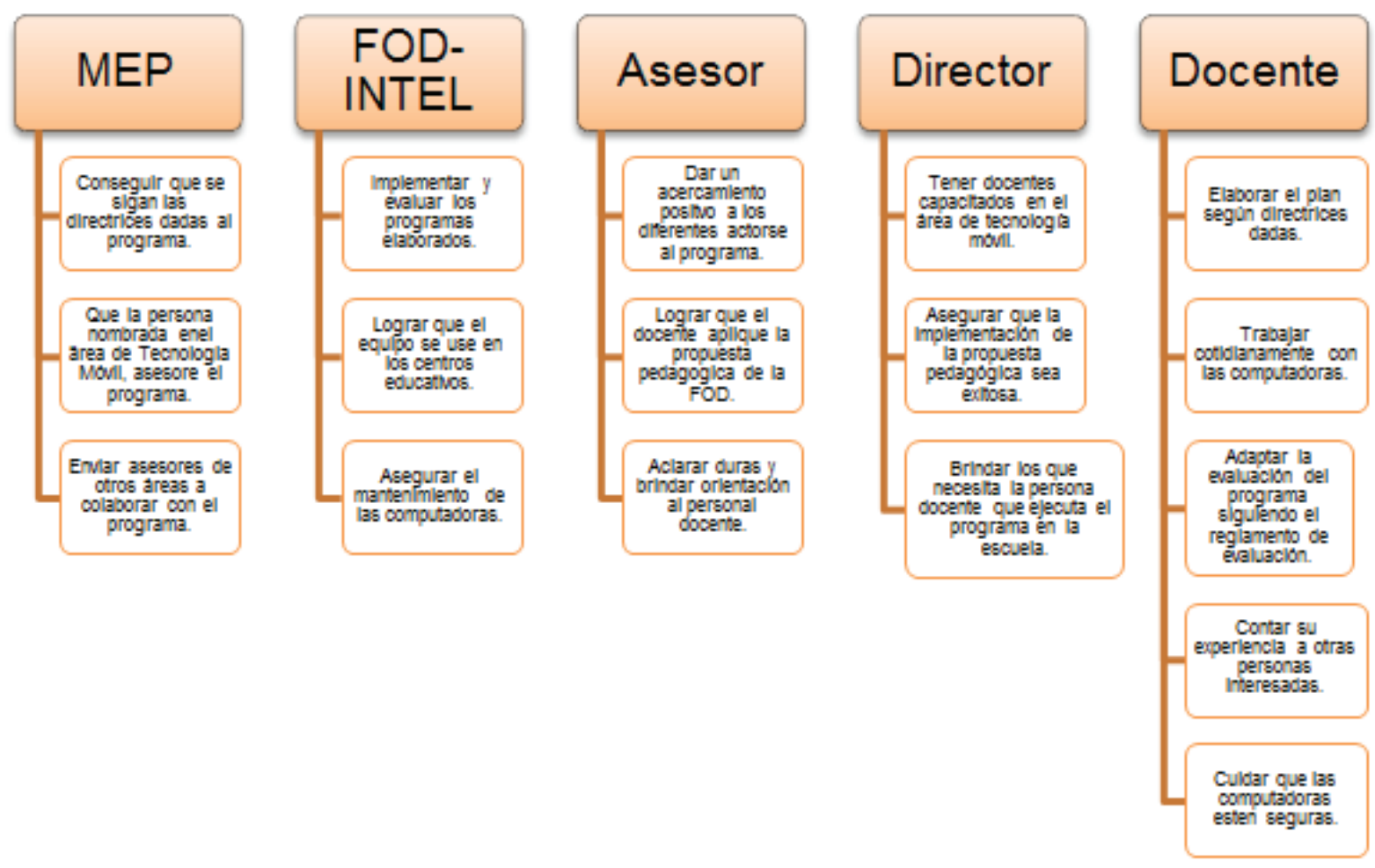

Figura 7. Estandarización de los resultados obtenidos por cada funcionario del programa

Nota: Entrevistas a profundidad a docentes y directores de los centros educativos, funcionario de la FOD y MEP, 2013.

Una vez que en el programa piloto se tiene clara la uniformidad de los procesos de trabajo, estos deberían asegurar que se alcancen los resultados esperados. En este sentido cada una de las entidades participantes debería tener claro lo que espera obtener con dicha implementación. 
Sin embargo, al no existir una uniformidad de los procesos de trabajo, los resultados no podrían ser estandarizados en ninguna de las instancias mencionadas. El profesional de la administración como gestor de cada centro educativo debe establecer una uniformidad de los procesos de trabajo para así poder comprobar los resultados esperados de una forma más fiable.

Tabla 6

Resumen de la estandarización de conocimientos y destrezas que profesionales directivos y docentes deberían adquirir antes de aplicar las TIC

Institución

FOD - MEP

\section{Estandarización de conocimientos y destrezas}

1. Conocimiento y comprensiones que van a adquirir y desarrollar: Constructivismo con fundamento pedagógico y metodologías como el aprendizaje por proyectos, por indagación, colaborativo y cooperativo, resolución de problemas, y pensamiento crítico.

2. La oportunidad que les permite a los usuarios el uso de las Classmate PC, son creación de un ambiente en el aula que fomente la construcción del aprendizaje por parte del estudiante.

3. La institucionalizarse estos recursos para generar mayores oportunidades de aprovechamiento. Entes facilitadores del proceso Estado, escuela, disposición del personal docente y flexibilidad y apertura de la persona directiva, una comunidad comprometida y familia que valoren el aprendizaje con el uso de tecnología.

4. La forma de innovar en las aulas escolares, considerando el aprendizaje significativo como la meta principal de la propuesta, ya que transforma en el proceso de enseñanza-aprendizaje.

5. Incorporación de tecnología móvil en la actividad del aula como recurso más que potencie enseñanza-aprendizaje.

6. La orientación de la acción pedagógica hacia el desarrollo integral del estudiante, ya que supone que el docente debe proporcionar al estudiante herramientas que le permitan trabajar con la Classmate PC.

7. El involucramiento del docente con un sentido de pertenencia y profesionalismo al cambio de paradigma.

Nota: Adaptado de Cubero, 2008a.

Los conocimientos y habilidades requeridos por las docentes que participaron en el programa piloto son que: deberían conocer y aplicar los fundamentos en relación con los siguientes aspectos: el constructivismo con fundamento pedagógico y metodologías como el aprendizaje por proyectos, por indagación, colaborativo y cooperativo, resolución de problemas, y pensamiento crítico.

\section{Aspectos que se pueden establecer como normas para el desarrollo adecuado del proyecto}

La administración de la educación supone que la estandarización de normas permite que los participantes puedan coordinarse, la carencia de este mecanismo obstaculiza que exista mayor participación. Siendo crucial que se detallen en un manual las normas básicas en cuanto al uso del equipo, por ejemplo: mantenimiento básico, guardado, control de su utilización, 
estrategias, entre otras. Al igual que en la escuela \# 2, en las otras escuelas no se tiene claridad sobre la forma en que se organiza el programa. Incluso comentan que a pesar de que el programa se desarrolla en once de las escuelas del circuito no existe una claridad en las normas básicas del programa en relación con los aspectos fuera del aula; pues el programa y las capacitaciones están enfocados en el cuerpo docente, por tanto, su gestión ha sido perjudicada por la falta de claridad en las normas de ejecución y unificación.

\section{Dirección que se da desde la administración al proyecto en cada escuela}

En la categoría de dirección se analizan los siguientes subcategoría: el liderazgo y el nivel de trabajo en equipo del programa, y se resumen la Figura 8.

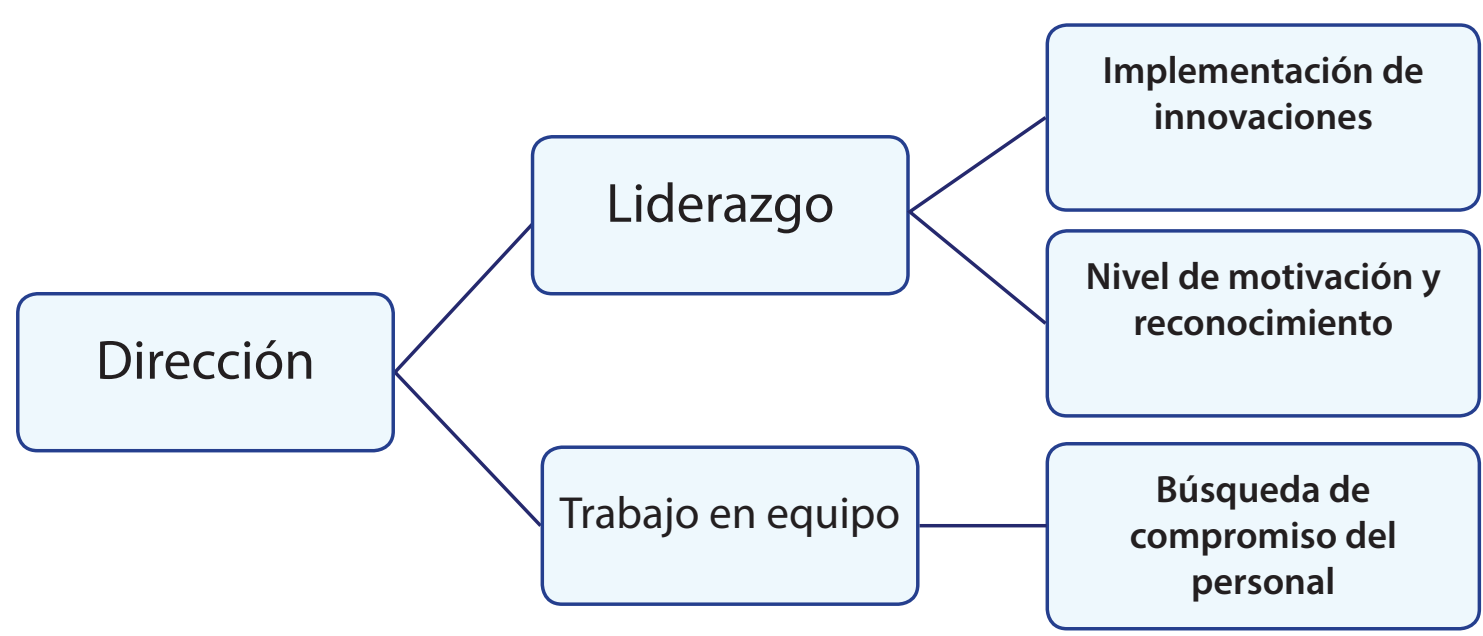

Figura 8. Categorías y subcategoría de la dirección de la organización Nota: Elaboración propia, 2013. 
Tabla 7

Síntesis de la categoría de dirección del programa

\begin{tabular}{lll}
\hline Categorías & \multicolumn{1}{c}{ Dirección } & \multicolumn{1}{c}{ Opiniones expresadas } \\
\hline \multirow{2}{*}{ Innovación } & $\begin{array}{l}\text { Desde la perspectiva de la dirección, cada persona } \\
\text { directiva ha dado al programa en su centro } \\
\text { educativo un propio proceso de innovación. }\end{array}$ & $\begin{array}{l}\text { Se puede destacar que en los centro educativo \#1 } \\
\text { y \#3 se muestra un interés de innovar las prácticas } \\
\text { pedagógicas. }\end{array}$ \\
\hline Motivación & $\begin{array}{l}\text { La dirección de este proyecto que vincula a } \\
\text { la escuela con la FOD y el MEP, no favorece el } \\
\text { desarrollo de estrategias que favorezcan la } \\
\text { motivación de los participantes. }\end{array}$ & $\begin{array}{l}\text { Por la falta de una visión compartida y metas } \\
\text { comunes que den una sola posición estrategia } \\
\text { ante las decisiones que involucran a los diferentes } \\
\text { interesados. }\end{array}$ \\
& & \\
\hline $\begin{array}{l}\text { Trabajo en } \\
\text { equipo }\end{array}$ & $\begin{array}{l}\text { Desde esta perspectiva el proyecto ha tenido varios } \\
\text { obstáculos en la búsqueda del verdadero trabajo en } \\
\text { equipo. }\end{array}$ & $\begin{array}{l}\text { En relación a lo interno de la organización el } \\
\text { principal impedimento ha sido el no contar con } \\
\text { suficiente equipo para involucrar a un mayor } \\
\text { número de docentes en el programa. }\end{array}$ \\
\hline
\end{tabular}

Nota: Entrevistas a profundidad a docentes y directores de los centros educativos y funcionarios del MEP y FOD, 2013.

Cada persona directiva ha dado al programa en su centro educativo un propio proceso de innovación principalmente enfocado a la mejora del proceso pedagógico del centro educativo. Se puede destacar que en los centro educativos \# 1 y \# 3 se muestra un interés de innovar las prácticas pedagógicas. La gestión, por tanto, ha facilitado que los procesos de implementación del programa se desarrollen con éxito y que aquellos docentes interesados se puedan acercar y participar de la iniciativa.

El programa ha tenido varios obstáculos en la búsqueda del verdadero trabajo en equipo. Esto porque en lo interno de cada centro educativo, el principal impedimento, ha sido el no contar con suficiente equipo para involucrar a un mayor número de docentes en el programa. Es necesario que la persona gestora logré que las personas involucradas contribuyan con sus ideas en la construcción de las metas colectivas.

\section{Indicadores de rendimiento de las acciones de evaluación.}

Para un gestor de la educación el proceso de evaluación debe realizarse empleando diferentes indicadores de rendimiento, en relación con las metas propuestas y las acciones realizadas. Por tanto la asignación de personas responsables del control del programa es necesario para realizar el proceso evaluativo en cada institución participante: FOD, MEP y escuelas. En la figura 9 se muestra la organización de los indicadores de rendimiento de las acciones de evaluación. 


\section{Indicadores de rendimiento de las acciones de evaluación}

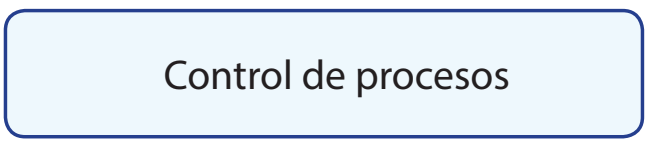

\begin{tabular}{|c|c|c|}
\hline $\begin{array}{c}\text { Asignación } \\
\text { de personas } \\
\text { responsables } \\
\text { del control }\end{array}$ & $\begin{array}{c}\text { Estrategias } \\
\text { de de control } \\
\text { adecuadas }\end{array}$ & $\begin{array}{c}\text { Nivel de } \\
\text { intervención } \\
\text { de las } \\
\text { carencias } \\
\text { detectadas }\end{array}$ \\
\hline
\end{tabular}

\section{Evaluación de resultados}

Técnicas
evaluativas
para medir el
alcance de la
promoción de
los estudiantes

Realimentación

\begin{tabular}{|c|c|c|}
\hline $\begin{array}{c}\text { Procesos de } \\
\text { intervención } \\
\text { para mejorar } \\
\text { el programa }\end{array}$ & $\begin{array}{c}\text { Divulgación } \\
\text { de resultados } \\
\text { en relación al } \\
\text { programa }\end{array}$ & $\begin{array}{c}\text { Establecimiento } \\
\text { de metas o } \\
\text { estrategias } \\
\text { que mejoren el } \\
\text { programa }\end{array}$ \\
\hline
\end{tabular}

Figura 9. Categorías, subcategorías e indicadores de rendimiento de las acciones de evaluación Nota: Adaptado de Robbins y Coulter, 2000.

\section{Control de procesos.}

En el programa la falta de claridad en la asignación de una persona encargada del proceso de control, significó que el mismo no se realizó con la formalidad necesaria en cada institución. Las estrategias de control aplicadas por cada una de las personas responsables se mencionan a continuación en la figura 10. 


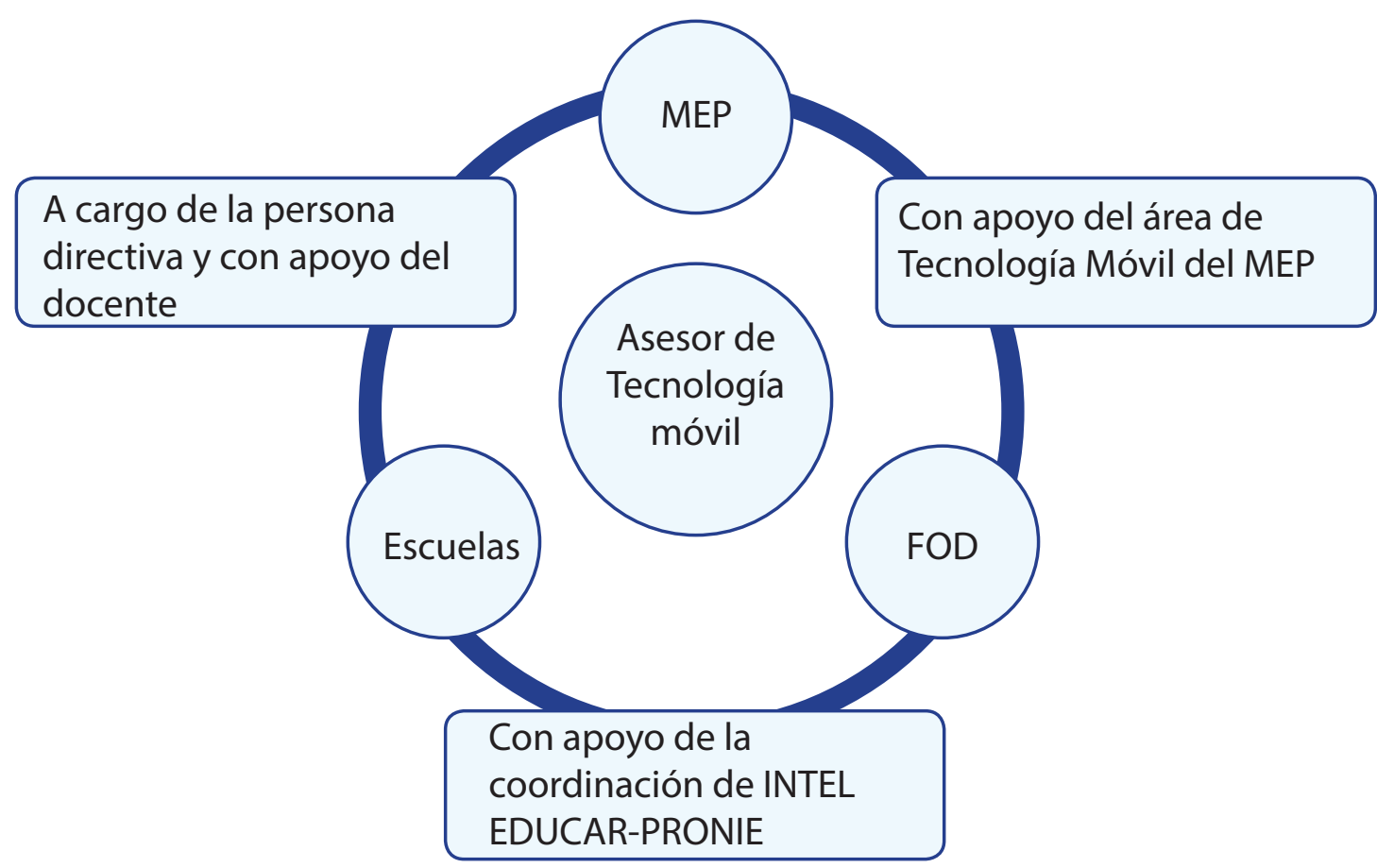

Figura 10. Persona que le correspondería el proceso de control en cada institución

Nota: Entrevistas a profundidad a docentes y directores de los centros educativos y funcionarios del MEP y FOD, 2013.

El asesor de tecnología móvil era el encargado de la FOD y el MEP para realizar la evaluación; sin embargo, las estrategias se enfocaron en hacer evaluaciones orales en los cierres de año. Esta evaluación indicó aspectos por mejorar pero no se concretaron acciones estratégicas en los centros educativos, en el FOD o en el MEP.

\section{Evaluación de resultados.}

El logro de una organización educativa se evidencia en la forma en que se hacen las cosas y en la calidad de la educación que recibe el alumnado. Por tanto, la persona gestora debe construir o utilizar diferentes técnicas que le permitan evaluar el alcance de la promoción de los estudiantes en el programa y responder acertadamente a las carencias que se iban detectando en el programa desde sus inicios. Estos resultados resumen la figura 11 y 12. 
1. Deficiencias de la Internet en cuanto a cobertura y mantenimiento de la red.

2. Deficiencias en el equipo donado, ya que no recibe mantenimiento del MEP o la FOD.

3. Falta de equipo tecnológico básico que complemente y facilite la labor docente.

4. La planificación de las lecciones porque implicaba muchos aspectos que eran difíciles de articular, considerando el desarrollo de la metodología por proyectos propuesta por la FOD.

5. Tener que compartir el equipo, entre docentes, para trabajar por áreas.

6. Falta de conocimiento del personal docente para trabajar en el programa.

7. Falta de vinculación de los padres con el programa.

8. Falta de articulación entre las diferentes instituciones participantes.

9. La inflexibilidad de la evaluación de los estudiantes, ya que les obstaculiza los procesos de aprendizaje.

\section{Figura 11. Principales carencias detectadas en el programa}

Nota: Entrevistas a profundidad a docentes y directores de los centros educativos y funcionarios, del MEP y FOD, 2013.

- El rendimiento académico es similar al de los otros grupos de paralelo. Pero las capacidades desarrolladas el estudiante van más allá de la nota sumativa.

- La capacidad de trabajar en equipo es una habilidad que los estudiantes no tenían al principio del proyecto, pero que han adquirido con el tiempo.

- La capacidad de exponer en público, la docente cuenta que esto fue un proceso de 3 años, pero después de ese tiempo los estudiantes le preguntar cuándo van a exponer porque ahora les encanta.

- Aprender a redactar fue también un reto, porque al principio ellos tenían un fólder de producciones textuales y luego se cambió por narraciones digitales, permitiendo que el alumnado pudiera ilustrarlo con imágenes y pudiera guardar el archivo en una llave maya.

- Un aspecto importantísimo que destacan las docentes es la disciplina, porque según indica mejoró mucho, además de la concentración y el análisis que ellos llegan a tener.

- La capacidad de realimentarse dentro del grupo se visto de manera muy positiva por el grupo, porque cuando los grupos ya tienen listos los proyectos y terminan de exponer, el grupo en general les hace una devolución que permite que los grupos mejoren su trabajo para la siguiente clase.

- Las habilidades para adaptarse al uso de diferentes paquetes de software ha sido una de las destrezas más importantes que desarrolla el alumnado. Algunos de estos programas son: Power Point, Excel, Word, Prezi, Cookies, Scratch, entre otros.

- En el trabajo cotidiano del aula el alumnado ha aprendido a usar las computadoras para hacer esquemas, resúmenes y mapas conceptuales, a pesar de que puede hacerse en el cuaderno el trabajar en las computadoras les encanta y los mantiene motivados.

- También para la hora de estudiar los temas para los exámenes se ha trabajado en hacer cuadros comparativos.

- Además esta docente indica que se mejora la responsabilidad, ya que cada estudiante asume de su trabajo es un gran logro. Porque, si a uno le toca un tema y no desarrolla correctamente, cuando comparte el proyecto con el grupo los demás no aprenden nada.

- $\quad$ El uso de herramientas diversas ha permitido que las clases sean más dinámicas y que cada estudiante.

Figura 12. Alcance de la promoción de los estudiantes en el programa

Nota: Entrevistas a profundidad a docentes y directores de los centros educativos y funcionarios del MEP y FOD, 2013. 


\section{Realimentación.}

En la Figura 13, se puede observar en resumen el proceso de realimentación del programa. Esta figura indica que en los tres centros educativos el proceso de realimentación de los resultados del programa debe enriquecerse en cuanto a la búsqueda más rigurosa de los resultados obtenidos, la divulgación de estos, el establecimiento de estrategias que faltan para renovar el programa y que permitan a mediano o largo plazo generar procesos de intervención para mejorar.

\section{Realimentación del programa}

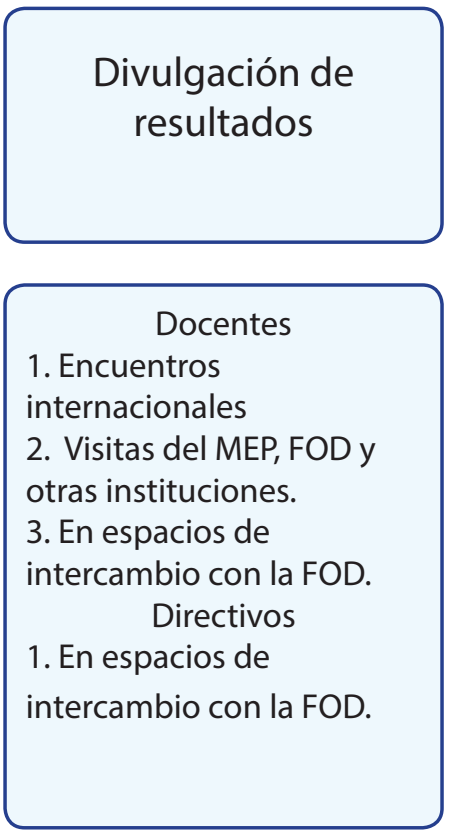

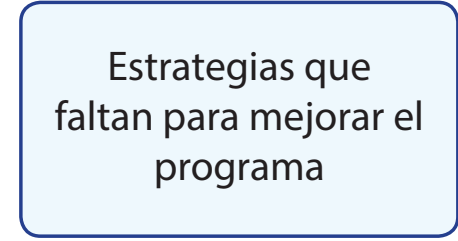

1. Se necesita mejorar la red inalámbrica.

2.Darle mantenimiento a las computadoras.

3. Reaccionar ante la falta de interés de la FOD por seguir apoyando el programa.

4. Darle continuidad a los estudiantes del programa en el colegio.

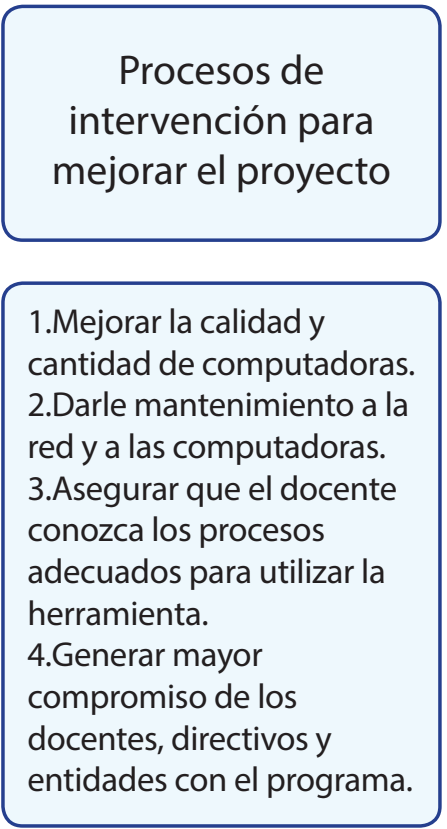

Figura 13. Resumen del proceso de realimentación del programa

Nota: Entrevistas a profundidad a docentes y directores de los centros educativos y funcionarios del MEP y FOD, 2013.

\section{Conclusiones}

Como conclusión general cada escuela debe tener un plan que responda a las expectativas tanto sociales y políticas del momento, en este sentido en relación con las TIC se debe invertir 
en recursos para incorporar las TIC en las aulas, este debe ser una meta para las gestoras de la educación de cada organización.

En relación con el programa de tecnología móvil en los tres centros estudiados, se debe comprender que por parte de la FOD y MEP existe el interés de que el programa continúe, pero no van a permanecer con el mismo acompañamiento a los centros educativos. Por tanto, en cada centro educativo la persona directiva debe ser capaz de gestionar de manera independiente el programa.

Por tanto, el gestor debe desarrollar estrategias que tengan lógica de realización y permitan la participación de la mayoría de los actores de la organización creando estrategias que le permitan concretar programas y desarrollar proyectos que orienten las acciones que se desarrollen en el centro educativo. Con el desarrollo de una planificación consensuada colectivamente y con un claro enfoque hacia el cumplimiento de los objetivos educativos para mejorar la calidad de la educación de los estudiantes.

Desde esta perspectiva, se propone el diseño de una serie de fases y pasos que orienten el proceso de gestión del programa en cada centro para que se desarrolle un proyecto institucional de tecnología en el aula. En dichas fases que corresponden a las etapas de la gestión, en cada una de ellas se establecerán pasos concretos que se deben ir desarrollando poco a poco para ir formulando inicialmente un plan que oriente el proceso del proyecto, para luego formar los equipos de trabajo internos y externos que los apoyarán, así como establecer mecanismos de coordinación que permitan mantener comunicación y estandarización de procesos básicos en el proyecto, para luego asegurar por medio de estrategias de control que se siga creciendo y mejorando el proyecto continuamente. Para que de esta forma su permanencia en los centros educativos esté asegurada y crezca con el paso del tiempo.

\section{Referencias}

Arroyo V., J.A. (2008). Hacia la delimitación de los conceptos: Teoría y Organización. (Borrador). Artículo proporcionado en el curso de Teoría de la Organización. Universidad de Costa Rica. San José, Costa Rica.

Barrantes E., R. (2010). Investigación: Un camino al conocimiento. San José, C.R.: EUNED.

Borges, J.L. (2000). El Aleph. España: Alianza.

Bateman, T.S. y Snell, S.A. (2009).Administración: liderazgo y colaboración en un mundo competitivo. México: McGraw Hill.

Chiavenato, I. (2007). Introducción a la Teoría General de la Administración. 7a Edición. McGraw Hill Interamericana: México. 
Consejo Nacional de Rectores [CONARE]. (2006). Plan Nacional de la Educación Superior Universitaria Estatal (PLANES) para el quinquenio 2006-2010. San José, Costa Rica: Autor.

Cubero, R. (2008a). Propuesta Pedagógica - Escuelas del proyecto: Tecnologías móviles en el ambiente escolar. Manuscrito inédito. Programa Intel Educar. Fundación Omar Dengo. San José, Costa Rica.

Cubero, R. (2008b). Tecnologías Móviles en el ambiente escolar: Manual para el docente. Borrador. Programa Intel Educar. Fundación Omar Dengo. San José, Costa Rica.

Eyzaguirre, N. (2006). La planificación estratégica como metodología integrada en el Sector Educación. (Ponencia XIX Seminario Regional de Política Fiscal - CEPAL-ILPES. TEMA: Planificación del Sector Público, gestión orientada a resultados y programación plurianual), 27p., s.l. Recuperado en: http://www.minedu.gob.pe/planificacionestrategica/xtras/MetodologialntegradaPE.pdf

Fayol, H. (1981). Administración industrial y general. Previsión, organización, mando, coordinación y control. Buenos Aires: El Ateneo.

Ferraro, A. (2012). Los dispositivos invaden las aulas. Monográfico 245 TIC y Educación. Educaweb. Recuperado en: http://www.educaweb.com/noticia/2012/01/30/dispositivos-movilidadinvaden-aulas-5220/

Francesc, P. (2006). Aprender en el nuevo milenio.Un desafío a nuestra visión de las tecnologías y la enseñanza. OECD-CERI.

Francesc, P. (2012).TIC y Educación: El éxito de las TIC en el aula no viene por la disponibilidad de los dispositivos ni por los contenidos, sino por los usos pedagógicos que transforman la enseñanza o el aprendizaje en procesos más eficientes. (Entrevista). Educaweb.com. Recuperado en: http://www. educaweb.com/noticia/2012/02/01/entrevista-francesc-pedro-tic-educacion-5248/

Gento, S. (1996). Instituciones educativas para la calidad total. Madrid: La Muralla.

Glennane, S. (2008). La inspección/Supervisión como espacio profesional específico. En: S. Gento (Coord.), Gestión y supervisión de centros educativos, pp.157-182. San José, Costa Rica: EUNED.

González, J. M.; Nieto, A. yPortela. (2003) Organización y gestión de centros escolares. Dimensiones y procesos. Madrid: Pearson Educación.

González S., Á. P. (2011). Evaluación para la mejora de los centros educativosWoltersKluvers. España.

Gurdián, F. A. (2007). El paradigma cualitativo en la investigación socio-educativa. Coordinación Educativa y Cultural Centroamericana (CECC) y Agencia Española de Cooperación Internacional (AECI). San José, Costa Rica.

Hernández, R.; Fernández, C. y Baptista, P. (2010). Metodología de la Investigación.México D.F.: Editorial McGraw Hill. 
Henao, Á. O. y Ramírez S., D.A. (2008). Un modelo de alfabetización que incorpora el uso de la tecnología de la información y la comunicación. Revista Educación y Pedagogía, 20(51), mayoagosto 2008. Universidad de Antioquia. Medellín, Colombia.

Lagos C., M.E. y Silva Q., J. (2011). Estado de las experiencias 1 a 1 en Iberoamérica. Universidad de Santiago de Chile. Revista Iberoamericana de Educación, 56, 2011, pp. 75-94. Universidad de Santiago de Chile. Santiago, Chile.

Mintzberg, H.; Quinn, J. B. y Voyer, J. (1997). Proceso Estratégico: conceptos, contextos y casos.México: Pearson Prentice Hall.

Morrissey, J. (2009).El uso de TIC en la enseñanza y el aprendizaje: cuestiones y desafíos. Recuperado en: http://coleccion.educ.ar/coleccion/CD30/contenido/pdf/morrisey.pdf

Pedreira, S.N. (2003). Un modelo de deuteroaprendizaje virtual.(Tesis Doctoral). Universidad de Coruña. Facultad de Informática. Coruña, España.

Prensky, M. (2009). Digital Wisdom (H. Sapiens Digital): MovingbeyondNatives and Immigrants. Innovate, 5(3). Recuperado de www.marcprensky.com

Programa Estado de la Nación. (2011). Tercer Informe Estado de la Educación. Capítulo 1: Sinopsis. San José, Costa Rica: Autor.

Organización para la Cooperación y el Desarrollo Económicos (OCDE) (2008) ¿Están preparados los estudiantes para un mundo de creciente demanda tecnológica? Revista Latinoamericana de Estudios Educativos, 37, pp. 157-210. México.

Reyes, H. C. (2000). Evolución de las Nuevas tecnologías y su aplicación en la Educación. Recuperado en: http://www.somece.org.mx/memorias/2000/docs/212.DOC

Robbins, S. P. y Coulter, M. (2000). Administración. México: Pearson Educación.

Rojas V., L.P. (2008). Elementos conceptuales y metodológicos de investigación cualitativa: modelo de autoinducción. San José, Costa Rica: Editorial UCR.

Trahtemberg, S. L. (2006). El impacto previsible de las nuevas tecnologías en la enseñanza y la organización escolar. Recuperado en http://www.educrea.cl/documentacion/articulos/tics/26_ impacto_previsible_nuevas_tecnologias_ensenanza_organizacion.html

Secretaría de Educación Pública [SEP]. (2009). Antología de Gestión Escolar. Programa Nacional de Carrera Magisterial. México. Recuperado de http://www.sepbcs.gob.mx/Carrera Magisterial/ Anto Ges Esc.pdf 